\title{
A MULTIPLE-INPUT SINGLE-OUTPUT DC-DC CONVERTER FOR THE DC HOUSE PROJECT
}

\author{
A Thesis \\ presented to \\ the Faculty of California Polytechnic State University, \\ San Luis Obispo
}

In Partial Fulfillment

of the Requirements for the Degree

Master of Science in Electrical Engineering

by

Chi Kin Taffy Wong

October 2011 
(C) 2011

Chi Kin Taffy Wong

ALL RIGHTS RESERVED 
COMMITTEE MEMBERSHIP

TITLE:

A Multiple-Input Single-Output DC-DC

Converter for the DC House Project

AUTHOR:

Chi Kin Taffy Wong

DATE SUBMITTED:

October 2011

COMMITTEE CHAIR:

Dr. Taufik, Professor

COMMITTEE MEMBER: Dr. Ahmad Nafisi, Professor

COMMITTEE MEMBER: Dr. Ali O. Shaban, Professor 


\begin{abstract}
A Multiple-Input Single-Output DC-DC Converter for the DC House Project Chi Kin Taffy Wong

October 2011

This thesis entails the design of a multiple-input single-output (MISO) dc-dc converter. The converter will be used to interface multiple power sources such as those obtained from renewable energy sources to a dc house. Results from the theoretical calculation and experimental data are presented in the report which demonstrate the functionality and performance of the proposed converter.
\end{abstract}




\section{TABLE OF CONTENTS}

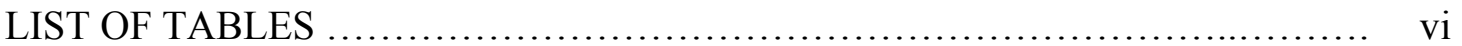

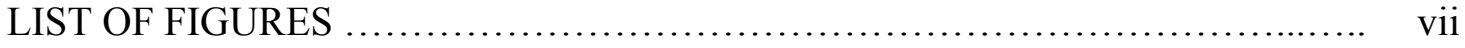

CHAPTER

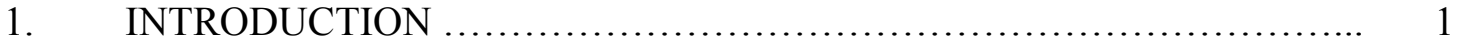

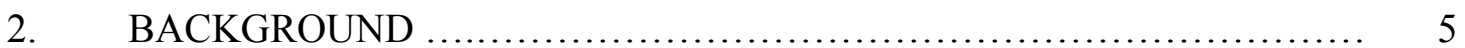

3. DESIGN SPECIFICATION ......................................... 11

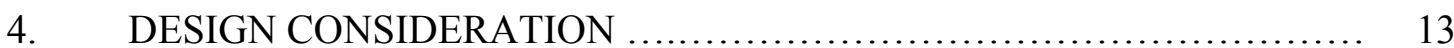

5. MEASUREMENTS AND ANALYSIS ............................... 25

6. IMPROVEMENTS AND FUTURE WORKS............................. 37

7. CONCLUSION ................................................... 42

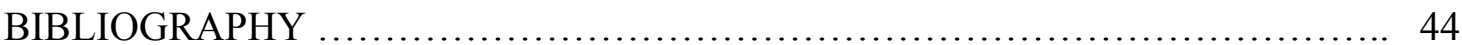

APPENDICES

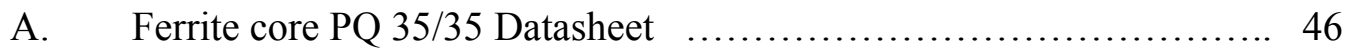

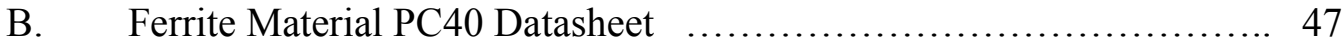




\section{LIST OF TABLES}

Table 3-1 - Specification of the multiple input single output DC-DC converter

Table 5-1 - Experimental Measurements of MISO converter

Table 5-2 - Performance Data of MISO converter 


\section{LIST OF FIGURES}

Figure 2-1 - Comparison of prices between DC and AC Power System 6

Figure 4-1 - Isolated full bridge converter

Figure 4-2 - Diagram of multiple input single output transformer 16

Figure 4-3. Full bridge switching signals and transformer switching waveform.... 18

Figure 4-4 - MISO transformer sandwich winding 19

Figure 4-5 - Schematic diagram of MISO converter

Figure 5-1 - Multiple input single output DC-DC Converter 25

Figure 5-2 - Complete MISO converter test setup 26

Figure 5-3 - Maximum output power of MISO converter 28

Figure 5-4 - Maximum output efficiency of MISO converter 29

Figure 5-5 - Output voltage ripple when MISO converter is powered by source A

Figure 5-6 - Output voltage ripple when MISO converter is powered by source A and $\mathrm{B}$ 30

Figure 5-7 - Output voltage ripple when MISO converter is powered by source A and $\mathrm{C}$ 30

Figure 5-8 - Output voltage ripple when MISO converter is powered by all sources .... 30

Figure 5-9 - CS voltage waveform when MISO converter is powered by one source ... 31

Figure 5-10 - CS voltage waveform with $0.25 \mathrm{~m} \Omega$ sense resistor 32 
Figure 5-11 - Layout of the MISO converter

Figure 5-12 - CS voltage waveform when MISO converter is powered by input A and $\mathrm{B}$

Figure 5-13 - CS voltage waveform when MISO converter is powered by input A and $\mathrm{C}$

Figure 5-14 - CS voltage waveform when MISO converter is powered by all sources 36

Figure 6-1 - Improved layout of the MISO converter 38

Figure 6-2 - MISO transformer with additional primary RC snubber circuit 38

Figure 6-3 - Improved MISO transformer sandwich winding 39 


\section{Introduction}

Since crude oil was introduced in the mid- $19^{\text {th }}$ century, it has become an irreplaceable energy source in the world. Crude oil powers up generators to generate electricity which provides a source of clean energy for our daily usage. Compared with burning fossil fuel directly, electricity is not only more efficient but also better in mobility and flexibility. Electrical energy can be transferred to any place with the use of transmission lines. Also, it can be converted to other forms of energy such as light, heat and kinetic energy per usage. Electrical machine doesn't require a ginormous combustion chamber to generate power; as a result, the reduction in size makes it more applicable in home usage. Nowadays, life is much easier with just a flip of the switch. Laundry which took half of a day to complete in the past can be done by washing and drying machines for only an hour or two. Electricity also brings us a safer kitchen. In the past, kerosene or natural gas were mainly used for cooking. This is not environmentally friendly, as the incomplete combustion causes air pollution. Also, fire is dangerous and not controllable when accident happen. Thanks to electricity, we now have electrical stoves which cook by heat. Electrical fault can be stopped by applying breakers while fault caused by other forms of energy will cease only when the energy source is completely consumed. This not only reduces the risk of fire at home, but also keeps our environment clean. One of the benefits is lighting. Kerosene lamps were mainly used for lighting in the past. Light generated from light bulbs lasts and becomes a reliable lighting source in the dark. Outdoor activities are no longer limited to the daytime, so people can work longer after sunset and factories can achieve higher productivity. There is no doubt that electricity improves our quality of life and helps countries to civilize into a modern age. 
From the early $20^{\text {th }}$ century, numerous technical papers and books on power electronics have been published. Many power electronic components, such as bipolar junction transistor, MOSFET and power diode were invented later. Compared with the bulky gas filled tubes, these components are smaller in size and operate more efficiently. Circuits built by power electronic components are capable of handling higher power and have more complex design. Due to wide spread use of power electronics, a lot of converter topologies have been studied. DC-DC topologies such as Buck, boost, Buckboost, Cuk and SEPIC provide us with the ability to step up or step down the input DC voltage to the desired voltage precisely. Topologies like Push-pull, Forward and Flyback give us the ability to convert $\mathrm{AC}$ to $\mathrm{DC}$ while providing isolation. Since power electronic circuits are controllable and relatively small compared with vacuum circuits, they have been widely adopted and further spur the development of a lot of electrical devices. Nowadays, electrical devices, such as laptops and cellphones, have become necessities in our daily life. These portable devices are small which provide us the mobility to learn and communicate.

There is no doubt that both electricity along with power electronics have become essential parts of our life. According to U.S. Energy Information Administration, energy consumption for the whole world is increasing every year and it is expected to reach 739 quadrillion Btu in 2035[1]. Many developing countries, such as China and India are industrialized and the power consumptions in these countries are increasing every year. However, because of the limitation of the power network, a lot of people in desolate areas in many countries are still living without electricity. Recent studies [2] indicate the fact that 1.6 billion people are living without electricity in the rural areas. People in these 
areas live in poor living environments and are disconnected with the rest of modern digitalized world. Some of the daily activities can still be accomplished by manpower, such as farming or pasturing. Also, knowledge is limited to potentially outdated books or by oral communication, so people are not able to keep up with the change to improve their quality of living. Although these areas lack electricity distributed from the power grid, there are plentiful renewable energy resources which can be used to generate electricity. If these renewable energies can be harvested and converted to $350 \mathrm{~W}$ to power a house for a day, it can power a typical $60 \mathrm{~W}$ light bulb which generates lighting after dark, a $55 \mathrm{~W}$ TV which provides a source of information and a $65 \mathrm{~W}$ laptop which allows people to connect to others on the web. Although $350 \mathrm{~W}$ seems to be not enough for our normal usage in the United States, it is enough to provide basic electricity in third world countries for appliances in homes and improve the standard of living.

Thanks to the advancement in power electronics, nowadays we have the soft switching and synchronous rectification technologies which help pushing power converters to operate as high as $85 \%$ efficient or more. Also, components used to convert renewable resources to electricity are getting more mature and are improved to run with high efficiency. For instance, solar panel made by Spectrolab can operate at $40.7 \%$ efficiency. Lots of research has been conducted to improve these rural areas by utilizing the available sustainable energy. Papers [2] and [3] introduce the idea of incorporating the available renewable energies in rural areas to generate electricity. Similar ideas have been further extended in [4] which propose to implement Photovoltaic power system in Mexico and Central America so as to provide distance education. Applying renewable energy source to generate electricity is not just limited to improve the standard of living 
in rural areas, but also to provide a future solution for the developed countries to replace the inefficient and polluting fossil fuels. Another application where renewable energy may benefit is reported in [5] and [6]. The papers reported studies to integrate renewable sources into more efficient transportation and the existing power system to make the power systems more robust, flexible and controllable. It can be concluded that sustainable energy is the future of energy source. 


\section{Background}

There have been so many discussions circling around the use of AC versus DC for power distribution. In fact, the question goes back to the time during the war between Edison's DC system versus Tesla/Westinghouse's AC system. Each system has its advantages and disadvantages, but at the time Edison's DC system lost its popularity due to the fact that it was very lossy to transmit DC power over a long distance. This was not the case for $\mathrm{AC}$, where voltage could be conveniently increased or decreased by using transformer. However, due to technical advancement in power electronics today those obstacles that Edison faced could be overcome. This further triggers the potential to use DC power again and the effort has recently been motivated by the progressive use of renewable energy sources which are mainly DC generators.

The disadvantages of AC system compared to DC system are summarized as follows. The first relates to the capacity of transmission line. Since the effective voltage of AC compared to DC is limited to $70.7 \%$ of the peak value; conductor with higher power rating is required to transmit the desired power. The capacity of AC line, unlike $\mathrm{DC}$, is also affected by power factor. Furthermore, AC is associated with reactance which causes the line to draw reactive power from the source and limits real power transmitted to the load. As a result, more conductors are needed to transmit power so as to prevent the conductors from overheating. AC is also known to possess the skin effect that creates additional losses in AC conductors. This is due to rearrangement of current distribution within the conductor where flowing current pushes to concentrate toward the surface of the conductor which reduces the total cross sectional area of conductor. As a result, the $\mathrm{AC}$ resistance of conductor increases. Another concern relates to the safety. Corona effect 
occurs when surface potential gradient of a transmission line exceeds the dielectric strength of the surrounding air and causes electrical breakdown. This fault has detrimental effect on the electrical insulators which has a tendency to damage the line protection.

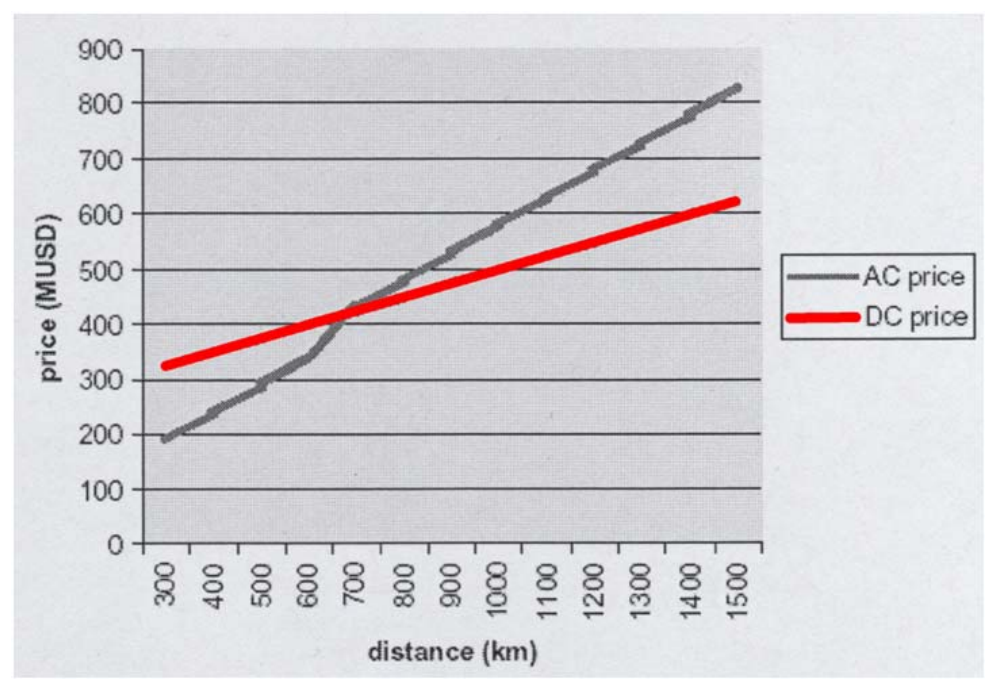

Figure 2-1. Comparison of prices between DC and AC Power System [7]

More and more power systems are now DC based due to the increase use of renewable energy sources which promotes the use of local distribution DC power network. DC has several advantages over its AC counterparts. According to Figure 2-1, the cost to setup a DC power system is cheaper when the overhead line distance is less than 500 miles. Also, DC line requires smaller towers so less space is needed to setup. The simplicity of connection simplifies the power system architecture in local area. Moreover, there is no alternating magnetic field around conductor, so inductive and capacitive effects do not exist. Inductive reactance of transmission line is zero and capacitance exists between conductors is open circuit for DC, so only real power is transmitted. Since power factor is always unity, reactance compensation is no longer 
necessary. Therefore, both power transfer capacity of the line and the efficiency of the system are higher. The frequency is always zero in DC supply; thus, no synchronous procedure is required to connect two DC power systems. This provides the ease to increase the system power when the demand is large. In addition, DC power flow is independent from the load and is controllable by adjusting the firing angles of the switches at the terminals. All the advantages suggest that DC power is more applicable in local residences.

Advantages of using DC power system especially for local distribution had brought us to the idea of setting up a DC home in the rural areas. These areas don't have tall buildings to block the sun light and wind flow; therefore, energy can be harvested to the fullest. Also, villages near rivers can also take advantage of hydro power as another DC power source. These DC based PV panel, hydro-turbine and wind turbine can be installed in each house. To extend the network, each individual home can also be connected in parallel to a single larger DC bus. This way, when there is a high demand of load in one home, the extra power can be easily fulfilled from the neighbors on the same DC bus. With a common DC bus, other DC sources can be tapped as another source of input power. In [8], power bike station has been installed in a primary school as an enhanced power source for a PV system. The power generated by the proposed station is proven to reduce 3 liters consumption per diesel fuel generator in every week. Playground may also provide a creative place for power generator while children play. However, to collect the energy from these sources using DC, a DC-DC converter is needed to convert power directly from the renewable sources to the desire voltage for the DC bus as well as to the individual DC load such as lamp and computer. This DC-DC 
converter must be designed to be efficient for the viability of DC home. At the end, by having a reliable and efficient DC house system, our dependence on the power grid could be eliminated and in turn DC house may eventually provide electricity for people in rural and remote areas to improve the quality of living.

Research has been conducted on all forms of renewable energies on methods to collect most of the renewable sources and techniques to improve the efficiency. Maximum Power Point Tracking(MPPT) is one of the common controlling techniques used in solar panel to maximize the input power to the converter by self-adjusting the load. In [9], MPPT is applied to control PV panels in a photovoltaic system. Ways to improve efficiency are not limited to MPPT. In [10], mirror is used as reflector to increase the solar intensity of the solar panel. Also, solar panel is connected to a motor. By using the rotary encoder, the motor moves the solar panel to track the sun's position. This method ensures maximum amount of direct normal sunlight to the solar panel. Experimental results in the paper show that the system outputs more power by using reflectors and tracker. In [11], a hybrid wind power system is simulated to run in isolated areas. The system also includes a diesel generator to supply power synchronously with the wind turbine during high demand of load and batteries to store the excess wind power. Two discharge strategies for the battery have been researched to reduce the operating cost. In [12], a hydro home system has been built and demonstrated in Nepal, where electricity is unavailable. The proposed system uses a motor dynamo to convert the kinetic energy of running water from a water tank to electricity. Power generated by the system is DC power which can be used to charge batteries and power up light and radio directly. 
The previous studies mentioned above successfully demonstrated their proposed solutions. However, all of them are optimized only for a single renewable source and most of them are connected to the power grid or generators as auxiliary backup power source. As discussed before, most of isolated areas lack the supply from power grid. Hence, dependence on one renewable source is not a reliable method to maintain a stable power system in these areas. Gathering energies from all kinds of available renewable resources to generate electricity seem to be the best solution in the rural areas. This calls for the use of multiple-input single-output DC-DC converter. There has been great interest in MISO in the recent years. In [13], six well-known DC-DC topologies have been researched to determine which topology is feasible to be modified as a multiple input power converter. The paper identifies some assumptions and introduces certain rules which are useful to define the characteristics of MISO. However, the study focuses mainly on non-isolated DC-DC conversion which is not applicable in our case. In [14] and [15], MISO is used to integrate all renewable energy sources into a DC bus. AC grid or DC battery is also connected to the converter to store excess power from the sources or deliver power to the load. In [16], [17] and [18], different kinds of isolated topologies have been deliberated for renewable energy system. Most of the MISO research is either proven on paper by simulation or limited to two kinds of renewable sources only. However, they provide fundamental work needed to support the proposed converter in this study.

The focus of this study is to design and build a multiple-input single-output DCDC converter to provide an interface between multiple DC sources and a single DC bus output. Solar power, wind power, and hydro power are abundant and unlimited in many 
areas in the world; therefore, they are used as energy sources to supply a single output voltage to a DC house. Since the proposed DC-DC converter is located in each DC house, reliability is one of the major considerations to confirm it is safe to operate. The design of this DC-DC converter will also focus on researching a suitable topology which integrates all renewable sources to a single output with low voltage ripple, tight line and load regulations without any sacrifice in overall efficiency. All performances will be confirmed by simulation and experimental measurements.

Chapter 1 of this thesis begins with a discussion of the benefits of electricity and power electronics which improves the living standard and plays an important role in world civilization and globalization. It also brings up an issue that many rural areas in the world today are still not connected with any electricity. The chapter concludes with an idea to provide rural electrification by sustainable energies. The history of AC and DC power is covered in Chapter 2 to depict the advantages and disadvantages of $\mathrm{AC}$ and DC power distributions. The chapter concludes with the expected achievement of the proposed Multiple-Input Single-Output DC-DC converter. Chapter 3 focuses on the specifications required for the proposed MISO converter. Critical component design calculations of the proposed converter are explained in Chapter 4. Chapter 5 records the experimental waveforms, efficiency, output voltage peak to peak ripple and load regulation of the proposed converter. Existing problems and possible future improvements are discussed in Chapter 6. This thesis is summarized in Chapter 7 to conclude this study. 


\section{Design Specifications}

As mentioned in the previous chapter, the objective of this thesis is to design and build a multiple-input single-output (MISO) DC-DC converter for the DC House project. The overall system efficiency of the converter is considered as a whole; therefore, not only the suggested DC-DC converter but also components in the system need to be researched and optimized to yield the most efficient operating voltage. To achieve the best efficiency, solar panel, DC wind turbine and DC hydro-turbine have been studied by other groups of students in the DC House project to determine the optimum output voltage. For this study, it will be assumed that maximum overall efficiency for these devices is achieved at $24 \mathrm{~V}$ output voltage. Hence, the input voltage of the proposed MISO is based on this value. It is assumed that in the initial phase of the DC House project, as many as three sources will be employed. Each renewable source output is also assumed to have a maximum power of $200 \mathrm{~W}$, so the total maximum input power of the proposed DC-DC converter is $600 \mathrm{~W}$. Major loads in the proposed DC house are low power devices, such as laptop, television and LED light, to provide communication and basic living necessities. Another assumption is that these devices are specified to operate at $48 \mathrm{~V}$ input voltage in order to achieve the highest efficiency. The proposed converter is therefore specified to output a maximum power of $350 \mathrm{~W}$ to the DC house at $48 \mathrm{~V}$.

Reliability of this converter is critical for home application. Since the peak input power is rated at $600 \mathrm{~W}$, it requires primary to secondary isolation to protect the user from connecting to the sources by accident. Also, one of the reasons for this converter to convert input DC voltage directly to DC output is to minimize the conversion loss. Therefore, the converter is expected to operate at $70 \%$ efficiency under full load. The 
$70 \%$ efficiency is chosen because it represents a good starting efficiency target for isolated topologies. This isolation can be achieved by using a transformer to step-up the input voltage; thus, the converter design should be based on isolated topology. In order to ensure the quality of the output voltage, output voltage peak to peak ripple should be less than $2 \%$ of specified $48 \mathrm{~V}$ output at full load and nominal $24 \mathrm{~V}$ input. Line and load regulations are also targeted to be less than 3\%. Table 3-1 summarizes the design requirements for the proposed converter.

Table 3-1: Specification of the multiple-input single-output DC-DC converter

\begin{tabular}{|l|l|}
\hline Number of input source & 3 \\
\hline Input source voltage & $24 \mathrm{~V}$ \\
\hline Maximum output wattage & $350 \mathrm{~W}$ \\
\hline Output voltage & $48 \mathrm{~V}$ \\
\hline Line regulation & $3 \%$ \\
\hline Load regulation & $3 \%$ \\
\hline Output voltage ripple & $2 \%$ \\
\hline Efficiency & $\geq 70 \%$ \\
\hline
\end{tabular}




\section{Design Considerations}

There are a lot of advantages to designing the proposed MISO based on full bridge topology. Compared with Push pull or Single forward transformer, full bridge transformer requires only one single primary winding for each input source. Since the MIC has three renewable sources, full bridge transformer requires only three primary windings in total which occupy less winding area and thus minimize the transformer size. Also, when all four MOSFETs at the bridge in Figure 4-1 are switched off, energy is recovered via the body diode. Therefore, reset winding on the primary side can also be eliminated. Compared with other isolated topologies, full bridge transformer is relatively smaller and requires less space on the circuit board to output the same amount of output power.

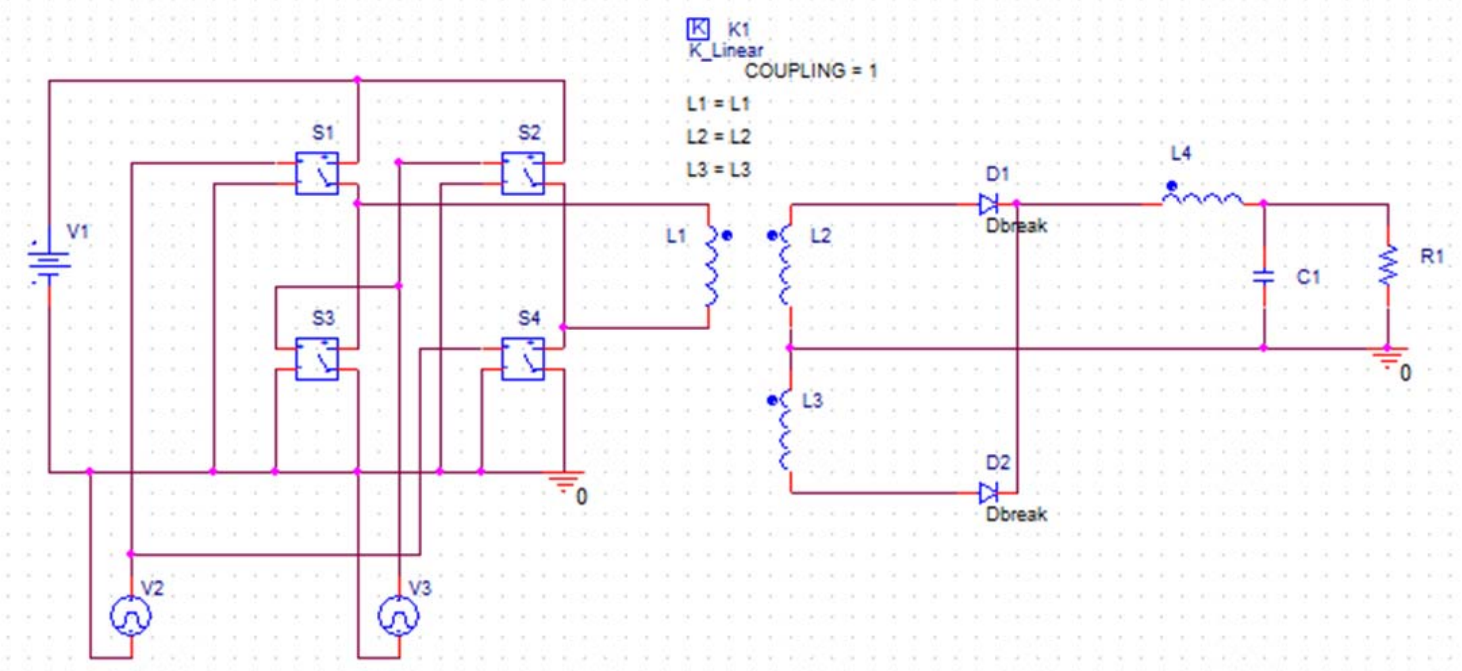

Figure 4-1. Isolated full bridge converter

In each switching cycle, the two MOSFETs in diagonal in the bridge rectifier are switched on alternatively for half a cycle. As a result, full-bridge converter delivers 
power to the output during both positive and negative switching cycle. Since the transformer drives in both directions, all four quadrants of the transformer's BH loop are used. In one cycle of operation under steady state condition, core's flux density swings up to $+\mathrm{B}$ and returns back to $-\mathrm{B}$ in the hysteresis loop of the ferrite core material. This avoids core's flux imbalance which drifts off the center of the hysteresis loop towards saturation region. Also, when two MOSFETs in diagonal are turned on, the maximum voltage stress across the other two turned off MOEFETs in steady state is inherently limited to the supply voltage. The intrinsic maximum voltage limiting feature avoids the use of snubber circuit thus minimizes clamped power loss across the switch.

On the secondary side, output is connected to two windings with a common center tapped connection. Two output rectifier diodes are connected in series in each winding and each diode conducts and rectify for half of a cycle. Since two rectified input pulses are sent to the transformer and reflected to the output stage in each period, the output voltage carries a frequency which is twice of the primary switching frequency. Higher ripple frequency reduces the output voltage ripple which requires less filtering at the output. Also, since the inductor is connected at the output stage, the continuous output current shares the same current characteristic as buck converter which requires smaller capacitor at the output. Obviously, smaller in size and better output quality makes full bridge topology more favorable in the DC home application.

Renewable sources can be connected in different patterns. One of the easy methods is to connect all sources in parallel on a single DC voltage bus. Overall power on DC bus can be adjusted by connecting or removing sources on the DC bus. Setting up a DC input bus is simple; however, all renewable sources on the bus are dependent to one 
another. When one of the sources is shorted to ground, the total power on the DC bus will drop to zero. Since most of the renewable sources depend on their sources which are not always available; therefore, it is not practical to apply this solution on the proposed multiple input single output converter.

Instead of connecting all renewable sources in parallel on a single DC bus, the addition of power can be performed inside the core of the transformer by the produced magnetic flux. According to Ampere's Law, Magnetomotive force (MMF) around a closed loop path $\ell \mathrm{c}$ inside the transformer core equals to the product of current and the number of turns.

$$
\text { MMF }=\left(\mathrm{H}_{1}+\mathrm{H}_{2}+\mathrm{H}_{3}\right) \ell \mathrm{c}=\mathrm{N}_{1} \mathrm{I}_{1}+\mathrm{N}_{2} \mathrm{I}_{2}+\mathrm{N}_{3} \mathrm{I}_{3}
$$

$\mathrm{N}_{1}, \mathrm{~N}_{2}$, and $\mathrm{N}_{3}$ are the number of turns of each of the three windings coupled on the primary side of the transformer and $\mathrm{H}_{1}, \mathrm{H}_{2}$, and $\mathrm{H}_{3}$ are the magnetic field intensity produced by the primary winding currents $\mathrm{I}_{1}, \mathrm{I}_{2}$, and $\mathrm{I}_{3}$ from each of the renewable sources. Since the MMF generated by each primary input winding is determined when all of the other sources are turned off, the resulted MMFs are linear which can be added up by using superposition. Also, magnetic field intensity $\mathrm{H}$, magnetic permeability $\mu$ of the core material, magnetic flux $\phi$, magnetic flux density $\mathrm{B}$, and the cross sectional area of the transformer core $\mathrm{A}_{\mathrm{c}}$ are related as follow:

$$
\begin{aligned}
& \mathrm{H}=\mathrm{B} / \mu \\
& \mathrm{B}=\phi / \mathrm{A}_{\mathrm{c}}
\end{aligned}
$$

From (4-2) and (4-3), MMF can be related to magnetic flux by: 


$$
\mathrm{MMF}=\left(\phi_{1}+\phi_{2}+\phi_{3}\right) \ell \mathrm{c} /\left(\mu \mathrm{A}_{\mathrm{c}}\right)
$$

By applying the theorem of superposition, total magnetic flux linkage inside the transformer core is the sum of magnetic flux $\phi_{1}, \phi_{2}$ and $\phi_{3}$ produced by primary winding currents from each renewable source. According to Lenz' law, an induced voltage is formed on the secondary side of the transformer which produces current that would cause a flux opposing the original flux change. As a result, secondary side output current is related to the sum of the total magnetic flux generated by the primary windings currents. Since the output voltage of each renewable source is regulated to $24 \mathrm{~V}$, all primary windings in the transformer share the same number of turns. Output voltage can be adjusted by the turns ratio of the primary and secondary windings. The proposed multiple primary windings transformer is depicted in Figure 4-2.

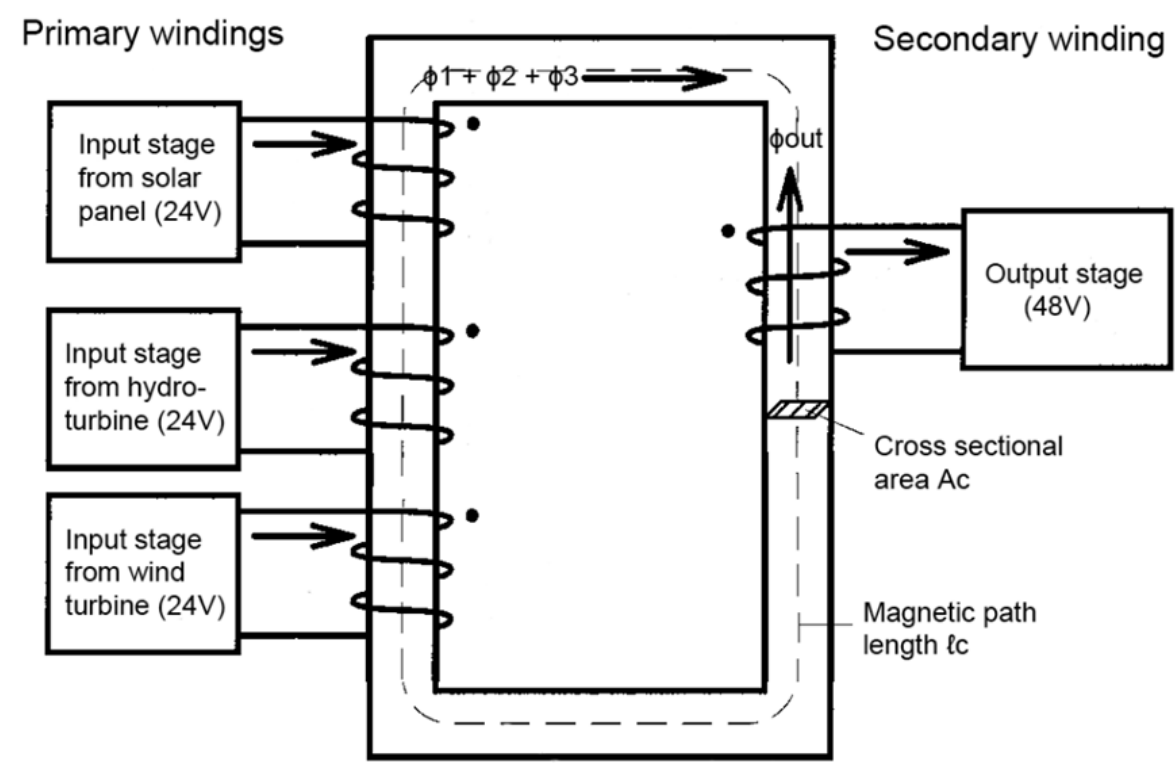

Figure 4-2. Diagram of multiple input single output transformer 
For DC home application, the transformer is designed to operate for a temperature rise of $50^{\circ} \mathrm{C} . \mathrm{PQ} 35 / 35$ ferrite core from Mag-inc is used for the transformer core and the ferrite core material is PC40. The minimum primary number of turns can be determined by using Faraday's Law,

$$
\mathrm{Np}=\left((\mathrm{V} * \mathrm{t}) /\left(\Delta \mathrm{B} * \mathrm{~A}_{\mathrm{e}}\right)\right.
$$

where $\mathrm{Np}=$ minimum primary number of turns

$$
\begin{aligned}
& \mathrm{V}=\text { applied DC voltage }-2 * \text { voltage drop caused by Rds(on) of two MOSFET (V) } \\
& \Delta \mathrm{B}=\text { maximum flux density (Gauss) } \\
& \mathrm{A}_{\mathrm{e}}=\text { minimum cross sectional area of core }\left(\mathrm{cm}^{2}\right) \\
& \mathrm{t}=\text { duration of changing flux ( } \mathrm{sec})
\end{aligned}
$$

To determine the minimum primary number of turns, we need to calculate the maximum flux density. Maximum flux density is provided by "Core loss vs. Flux density" curve given with the core material. Using the "Temperature rise vs. Total loss for PQ $35 / 35$ core" curve in appendix A, the core dissipates $3.25 \mathrm{~W}$ when its temperature rises $50^{\circ} \mathrm{C}$. Assuming core losses and copper losses are evenly distributed in the transformer, the core loss will be $1.625 \mathrm{~W}$. Therefore, the maximum core loss density is:

$$
\text { Pcore loss }=\text { Pcore } / \mathrm{Ve}
$$

where $\mathrm{Ve}$ is the effective core volume of the core, so

$$
\text { Pcore loss }=1.625 \mathrm{~W} / 17.3 \mathrm{~cm}^{3}=93.9 \mathrm{~mW} / \mathrm{cm}^{3}
$$




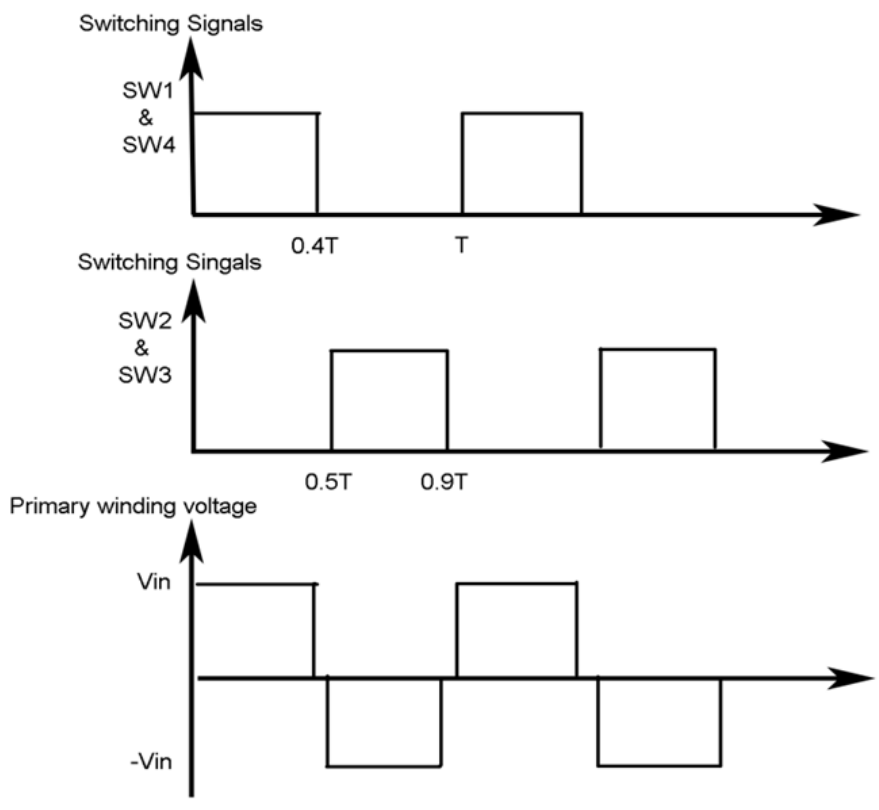

Figure 4-3. Full bridge switching signals and transformer switching waveform

The switching frequency is set to $200 \mathrm{kHz}$ for the MISO. From Figure 4-3, each pair of diagonal MOSFETs turn on for $0.4 \mathrm{~T}$ and turn off for $0.1 \mathrm{~T}$, also, the transformer takes $\mathrm{T}$ period to complete the switching cycle. Therefore, the transformer switching frequency is half of the switching frequency, which is $100 \mathrm{kHz}$. Using "Core loss vs Flux density" curve in Appendix B, the peak flux density is approximately 1200 Gauss. To prevent the core from operating in saturation region, 600 Gauss will be used in the transformer design. The maximum duty cycle is set to $80 \%$ of the maximum on time so as to prevent the top and bottom MOSFETs in the full bridge from switching on at the same time and shorting the input source. Therefore, the maximum flux density change within $0.8 / 2$ will be $2 * 600$ Gauss. Also, voltage drop caused by Rds(on) of each MOSFET is assumed to be $1 \mathrm{~V}$ drop. Using (4-5),

$$
\mathrm{Np}=\left((24 \mathrm{~V}-2 * 1 \mathrm{~V}) *(0.8 * 4.878 \mu \mathrm{s} / 2) * 10^{8}\right) /\left(1.96 \mathrm{~cm}^{2} * 2 * 600 \text { Gauss }\right)
$$


Output voltage can be determined by using (4-9),

$$
\mathrm{Vo}=\mathrm{Vin} *(\mathrm{Ns} / \mathrm{Np}) * \mathrm{D}
$$

Output is selected to be $48 \mathrm{~V}$, so the number of secondary turns is:

$$
\begin{aligned}
\mathrm{Ns} & =(\operatorname{Vo} /(\operatorname{Vin} * \mathrm{D})) * \mathrm{~Np} \\
& =(48 /(24 * 0.8)) * 2 \\
& =5 \text { turns }
\end{aligned}
$$

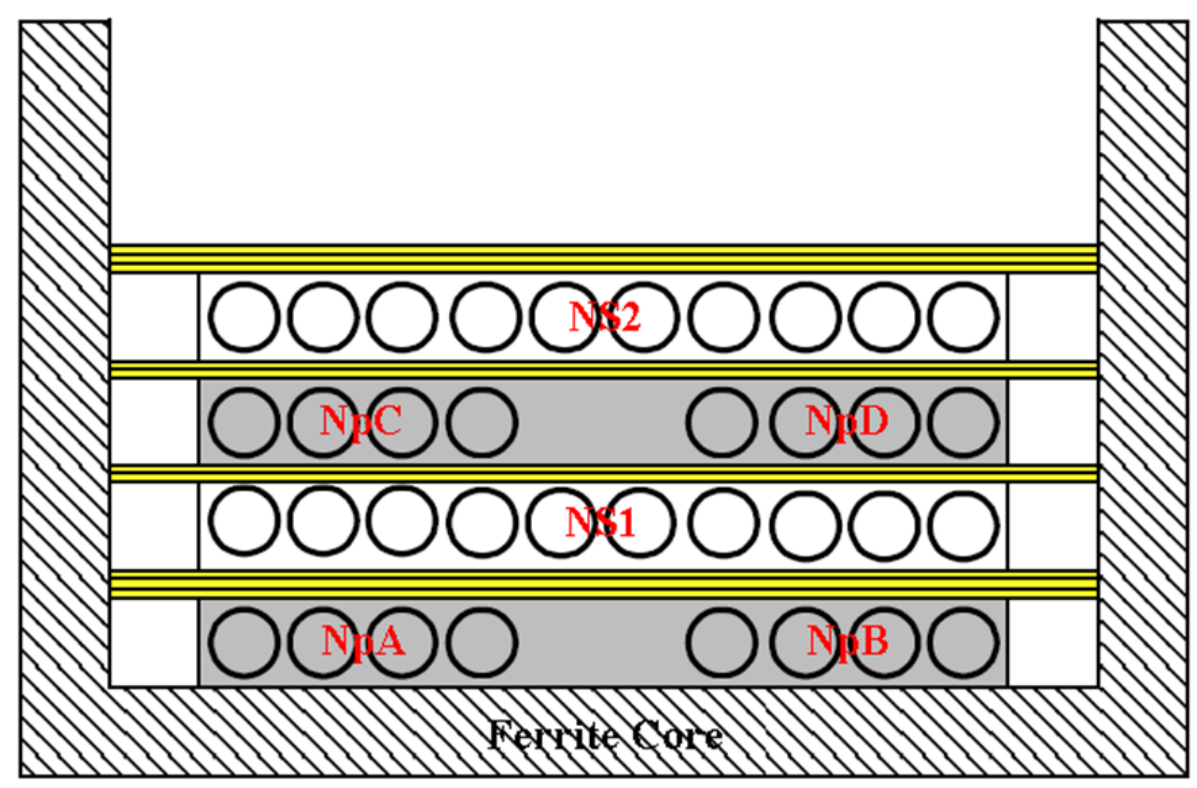

Figure 4-4. MISO transformer sandwich winding

In order to reduce proximity effect between primary and secondary windings inside the transformer, primary and secondary windings in the MISO transformer are constructed in sandwich winding pattern to achieve high efficiency. The sandwich 
winding pattern of the MISO transformer is shown in Figure 4-4. In Figure 4-4, NpA, $\mathrm{NpB}, \mathrm{NpC}$ and $\mathrm{NpD}$ are the primary windings connected to the input sources. In this study since only three input sources are used, NpD is not connected. Ns1 and Ns2 are connected in parallel to the output rectifiers. According to (4-8) and (4-10), the ratio $\mathrm{Np}:$ Ns is $2: 5$. In the transformer, 4 turns are used in each primary winding and 10 turns are used in the secondary windings so as to maximize the winding space. The sandwich pattern $\mathrm{Np} / \mathrm{Ns} / \mathrm{Np} / \mathrm{Ns}$ is used so that when all windings are loaded, the proximity effect between adjacent windings is minimized.

Schematic of the proposed MISO is shown in Figure 4-4. LTC3723-1 PWM controller is used to drive the gate of four MOSFETs on the bridge. This controller features current mode control which uses resistive sensing on the primary side to control the maximum switching current. An error voltage across the sense resistor is used to compare with an internal $300 \mathrm{mV}$ nominal threshold. The PWM cycle stops once the $300 \mathrm{mV}$ threshold is exceeded; as a result, four primary switches are protected from breaking down by overcurrent fault. Paper [19] explains that reflected DC output current with ripple current included, primary side magnetizing current and the downslope output inductor current are the major factors which define the shape of the current waveform through the current sensing resistor. In the hardware circuit, $10 \mathrm{~m} \Omega$ is selected as the current sensing resistance and the CS pin of the controller is tied to source 1 in the test setup. 

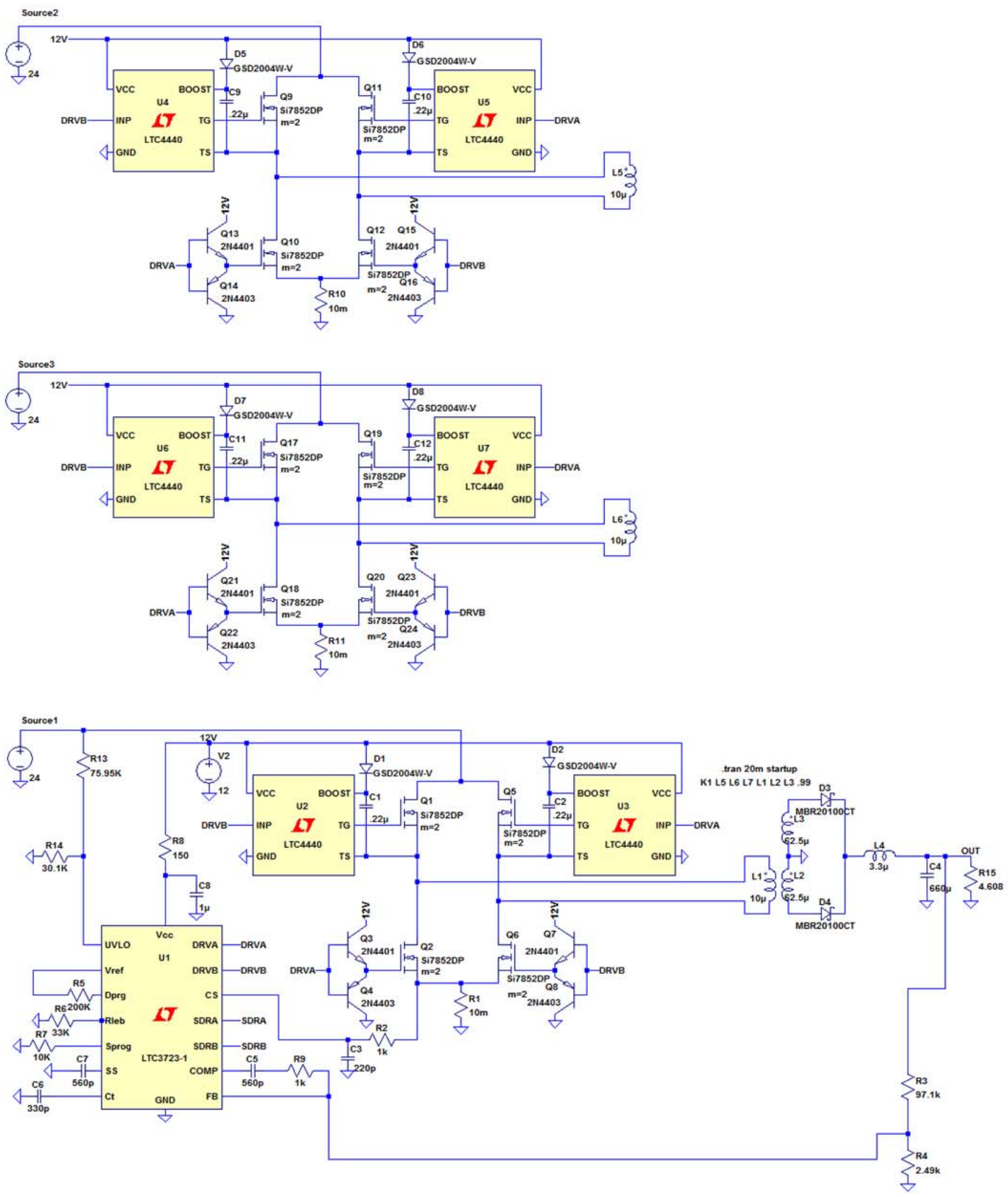

Figure 4-5. Schematic diagram of MISO converter 
Leakage inductance from the transformer can create a high error voltage spike at the current sense resistor during switch off. When the voltage spike exceeds $300 \mathrm{mV}$, controller will false trigger the overcurrent protection inside the controller and stop the PWM from sending switching signals to the MOSFET on the bridge. This requires heavy filtering to diminish the spike. However, the false trigger can also be fixed by using the Leading Edge Blanking provided by the controller. A resistor tied from pin $\mathrm{R}_{\mathrm{LEB}}$ to ground programs the blanking time which delays the comparator to read the error voltage from the current sense resistor. The duration of the spike is measured on hardware, and $33 \mathrm{k} \Omega$ is used to set up the proper delay time.

Since the proposed converter has three input sources, the gate signal needs to drive six MOSFETs for each half cycle. The signals to each bridge have to be synchronized; otherwise, two input sources will be shorted when one of the bridges is operating in positive half cycle while the other bridge is running in negative cycle. Three input sources can be controlled by three separate controllers; however, external frequency source is required to maintain the controllers to operate synchronously. Also, since the PWM in each controller senses the feedback voltage from the output to adjust the duty cycle, external logic circuit is needed to differentiate the feedback voltage to each controller. Instead of using three controllers, it can be done also by using one controller only. Since MOSFET drivers on the controller are designed to drive two switches on the bridge, Totem Pole is needed to boost the signal. In a totem pole output, two transistors are stacked one above the other and one transistor will be used in a commonemitter configuration while the other is used as an emitter follower. Drive signal is sent to the base of both transistors and the output of totem pole is supplied by the $12 \mathrm{~V}$ source. 
Using totem pole to drive MOSFETs draws less current from the controller so that the same signal can be used to drive more MOSFETs. In figure 4-4, totem pole is used to drive the low side MOSFETs while the high side MOSFETs are driven by the LTC4440 high side gate drivers.

Switching frequency is programmed by using a capacitor connected to the $\mathrm{C}_{\mathrm{T}}$ of the controller. According to the datasheet of the controller,

$$
\mathrm{C}_{\mathrm{T}}=1 /\left(14.8 \mathrm{k} * \mathrm{~F}_{\mathrm{sw}}\right)
$$

Setting the switching frequency to $200 \mathrm{kHz}$, the capacitance needed is,

$$
\mathrm{C}_{\mathrm{T}}=1 /(14.8 \mathrm{k} * 200 \mathrm{kHz})=337.84 \mathrm{pF} \approx 330 \mathrm{pF}
$$

Output inductor limits the amount of output current ripple. From element laws,

$$
\Delta \mathrm{i}_{\mathrm{L}} / \Delta \mathrm{t}=\mathrm{V}_{\mathrm{L}} / \mathrm{L}
$$

Assume the voltage across the inductor $\mathrm{V}_{\mathrm{L}}$ is constant, output ripple current $\Delta \mathrm{i}_{\mathrm{L}}$ decreases as the output inductance increases. Minimum output inductance can be determined by using formula (4-14),

$$
\begin{aligned}
\text { Lout }_{\text {min }} & =(0.5 * \text { Vo }) /\left(\text { Io } * f_{\mathrm{sw}}\right) \\
& =(0.5 * 48) /(7.29 * 200000) \\
& =1.37 \mu \mathrm{H}
\end{aligned}
$$

In the circuit, $3.3 \mathrm{uH}$ inductor is used at the output. 
Output capacitor filters out the output voltage ripple. According to the specification of the MIP converter stated in Chapter 3, maximum output voltage ripple $\mathrm{V}_{\text {ripple }}$ should be less than $2 \%$, i.e.

$$
\mathrm{V}_{\text {ripple }}=48 * 2 \%=0.96 \mathrm{~V}_{\mathrm{pk}-\mathrm{pk}}
$$

Therefore, the minimum output capacitance can be calculated using formula (16),

$$
\begin{aligned}
\mathrm{Co}_{\min } & =\left(50 * 10^{-6} * \Delta \mathrm{i}_{\mathrm{L}}\right) / \text { Vripple } \\
& =\left(50 * 10^{-6} * 2.1875\right) / 0.96 \\
& =113.93 \mu \mathrm{F}
\end{aligned}
$$

Again, according to element laws,

$$
\Delta \mathrm{V}_{\mathrm{C}} / \Delta \mathrm{t}=\mathrm{i}_{\mathrm{C}} / \mathrm{C}
$$

Assuming the capacitor current $\mathrm{i}_{\mathrm{C}}$ is constant, higher output capacitance $\mathrm{C}$ reduces the output voltage ripple $\Delta \mathrm{V}_{\mathrm{C}}$. In reality, electrolytic capacitor has an internal ESR resistance in series with the capacitance. This resistance dissipates power during conduction which causes power loss and reduces efficiency. To minimize the ESR, multiple capacitors can be connected in parallel at the output. In the actual circuit, two $330 \mu \mathrm{F}$ are connected in parallel at the output so as to lower the power loss from ESR. 


\section{Measurements and Analysis}

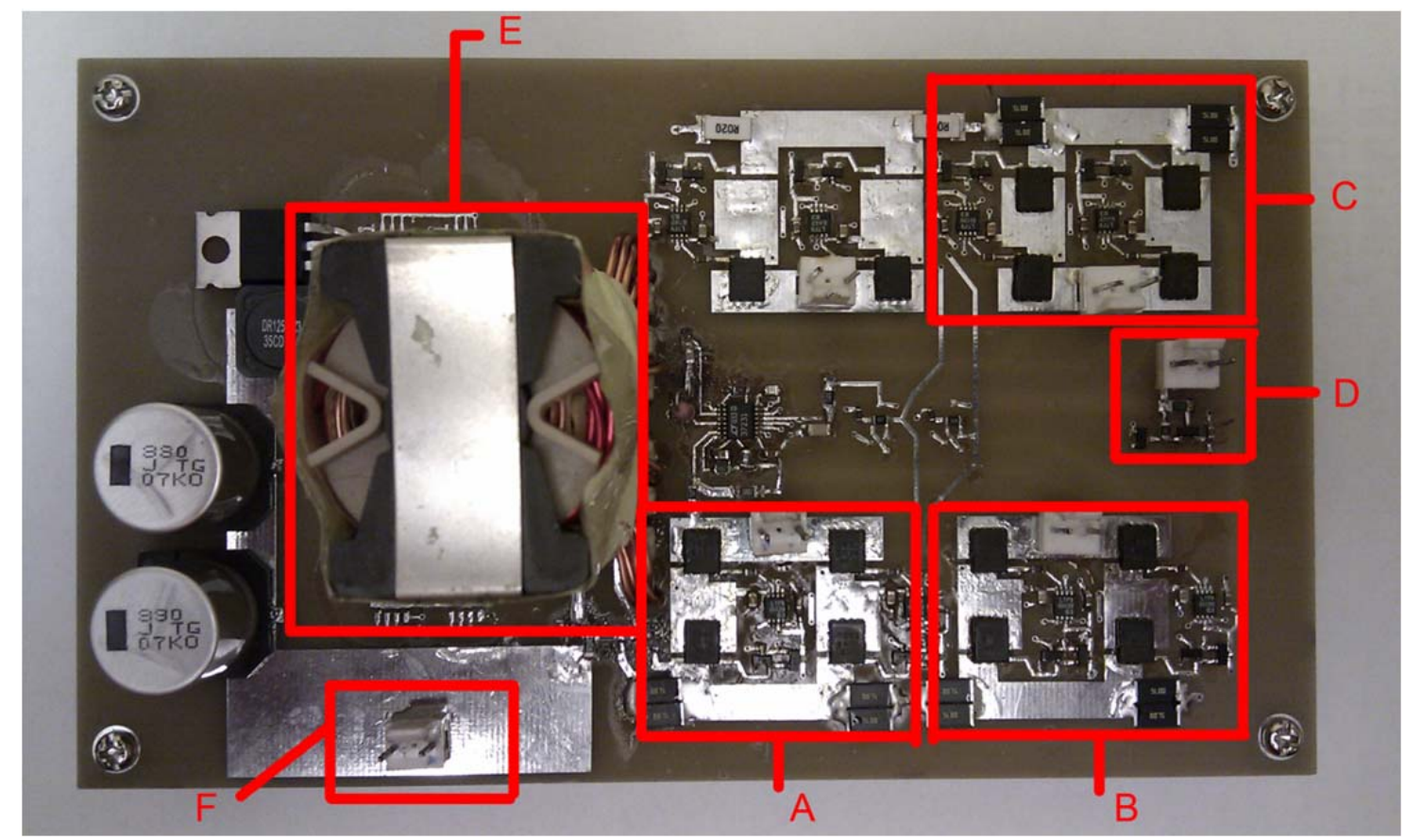

Figure 5-1. Multiple-input single-output DC-DC Converter

The proposed MISO converter hardware is shown in Figure 5-1. Input (A), (B) and (C) are the primary full bridge for the three renewable sources. Input (D) powers LTC3723-1 controller and LTC4440 high side gate drivers separately from the input sources. In DC house application; this can be a small battery box so that controller's operation is independent of the renewable sources. (E) is the multiple input single output full bridge transformer. After output diode, inductor and capacitor, output $(\mathrm{F})$ is the $48 \mathrm{~V}$ output supply to DC home.

Figure 5-2 shows the complete test setup in the lab. Three DC power supplies on the top, which are used to simulate the three renewable input sources, are connected to inputs A, B and C of MISO converter. The fourth DC source is connected to input D in 
Figure 5-1. Electronic load on the bench table is connected to output of MISO converter which is used to simulate the total load in DC house.

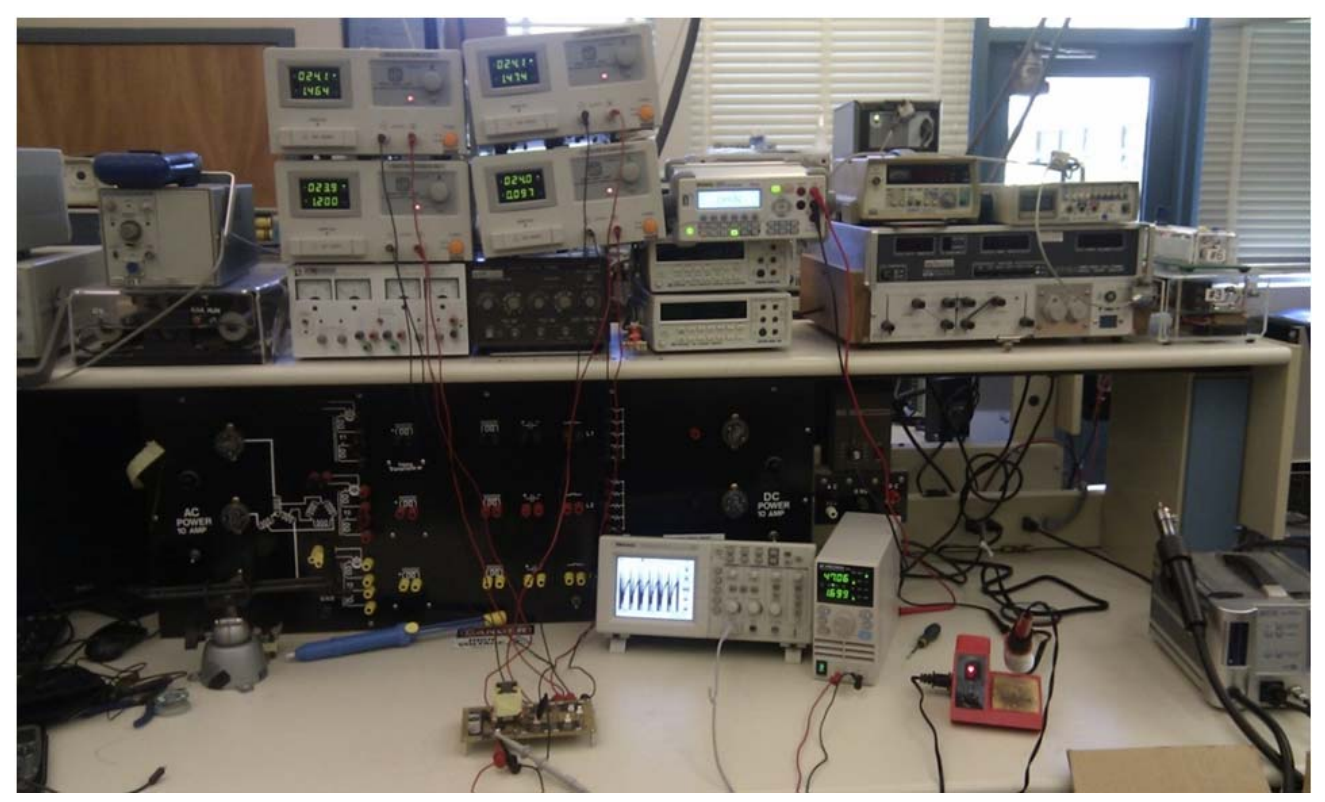

Figure 5-2. Complete MISO converter test setup

As discussed in the last chapter, the primary current from source A is used to generate the corresponding error voltage waveform to the current sense pin of the controller. As a result, source B and source C can't power the output load without turning on source A. In the hardware demonstration, the MISO converter hardware was tested under different conditions: only source A is turned on, source A and source B are turned on, source A and source $\mathrm{C}$ are turned on and all sources are turned on. The current sense voltage waveform will be monitored to ensure the MISO converter is running at maximum output before switching current folds back. All voltages and currents from the input sources and to the output are recorded in Table 5-1. Performance data of the MISO converter, such as output peak to peak ripple, load regulation and efficiency are recorded in Table 5-2. 
Table 5-1: Experimental Measurements of MISO converter

\begin{tabular}{|c|c|c|c|c|c|c|c|c|c|c|c|}
\hline Case & $\begin{array}{l}\text { VsA } \\
\text { (V) }\end{array}$ & $\begin{array}{l}\text { IsA } \\
\text { (A) }\end{array}$ & $\begin{array}{l}\text { VsB } \\
\text { (V) }\end{array}$ & $\begin{array}{l}\text { IsB } \\
\text { (A) }\end{array}$ & $\begin{array}{l}\text { Vsc } \\
\text { (V) }\end{array}$ & $\begin{array}{l}\text { Isc } \\
\text { (A) }\end{array}$ & $\begin{array}{l}\text { VsD } \\
\text { (V) }\end{array}$ & $\begin{array}{l}\text { IsD } \\
\text { (A) }\end{array}$ & $\begin{array}{l}\text { Vout } \\
\text { (No } \\
\text { load) }\end{array}$ & $\begin{array}{l}\text { Vout } \\
\text { (Full } \\
\text { load) }\end{array}$ & Iout \\
\hline $\begin{array}{c}\text { All } \\
\text { sources } \\
\text { on } \\
\end{array}$ & 23.9 & 1.200 & 24.1 & 1.464 & 24.1 & 1.474 & 24.0 & 0.097 & 48.55 & 47.15 & 1.699 \\
\hline $\begin{array}{c}\text { Input } \\
\text { source A } \\
\& \text { Input } \\
\text { source B } \\
\text { on } \\
\end{array}$ & 23.9 & 1.245 & & & 24.1 & 1.355 & 24.0 & 0.09 & 48.65 & 48.28 & 0.999 \\
\hline $\begin{array}{c}\text { Input } \\
\text { source A } \\
\& \text { Input } \\
\text { source C } \\
\text { on } \\
\end{array}$ & 23.8 & 1.684 & 24 & 1.881 & & & 23.9 & 0.085 & 48.56 & 47.31 & 1.399 \\
\hline $\begin{array}{l}\text { Only } \\
\text { Input } \\
\text { Source } \\
\text { A on }\end{array}$ & 23.5 & 2.188 & & & & & 24.1 & 0.081 & 48.63 & 48.38 & 0.799 \\
\hline
\end{tabular}

In Table 5-1, VsA, VsB and Vsc correspond to the input voltages from input source A, B and C. Also, IsA, IsB and Isc correspond to the input currents from input source A, B and C. VSD and IsD are the voltage and current supplied by the input source $\mathrm{D}$ which is used to power up the controller and high side gate drivers. Moreover, Vout and Iout correspond to the voltage and current supply to the DC house.

Table 5-2: Performance Data of MISO converter

\begin{tabular}{|c|c|c|c|c|}
\hline Case & $\begin{array}{c}\text { Max Output } \\
\text { power(W) }\end{array}$ & $\begin{array}{c}\text { Ripple } \\
(\mathrm{mV})\end{array}$ & Efficiency (\%) & Load Reg (\%) \\
\hline All sources on & 80.1 & 600 & 78.68 & 2.97 \\
\hline $\begin{array}{c}\text { Input source A \& Input } \\
\text { source B on }\end{array}$ & 48.2 & 456 & 74.70 & 0.77 \\
\hline $\begin{array}{c}\text { Input source A \& Input } \\
\text { source C on }\end{array}$ & 66.2 & 432 & 75.85 & 2.64 \\
\hline Only Input Source A on & 38.7 & 264 & 72.43 & 0.52 \\
\hline
\end{tabular}


In Table 5-2, maximum output power is calculated by using (5-1).

$$
\text { Output power }=\text { Vout }_{\text {Full Load }} * \text { I out }
$$

Efficiency is calculated by using (5-2),

Efficiency $=$ Output power*100\%/ $\left(\mathrm{VSA}^{*} \mathrm{ISA}+\mathrm{VSB}^{*} \mathrm{ISB}_{\mathrm{SB}}+\mathrm{VSC}^{*} \mathrm{ISC}_{\mathrm{SC}}+\mathrm{VSD}^{*} \mathrm{ISD}\right)$

Load Regulation is calculated by using (5-3),

$$
\text { Load Regulation }=\left(\text { Vout }_{\text {No Load }}-\text { Vout }_{\text {Full load }}\right) / \text { Vout }_{\text {Full load }}
$$

The output power and efficiency data are plotted in Figure 5-3 and Figure 5-4.

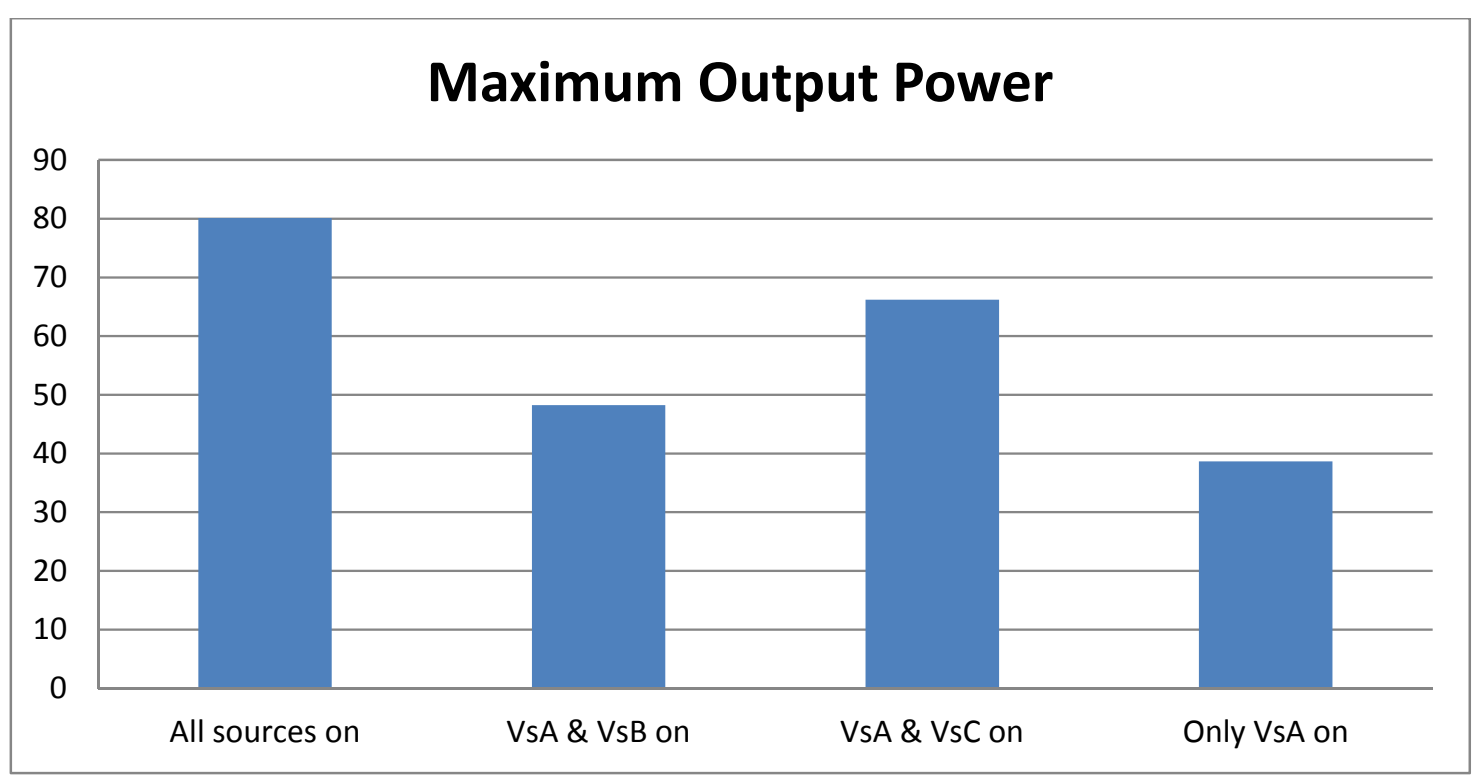

Figure 5-3. Maximum output power of MISO converter 


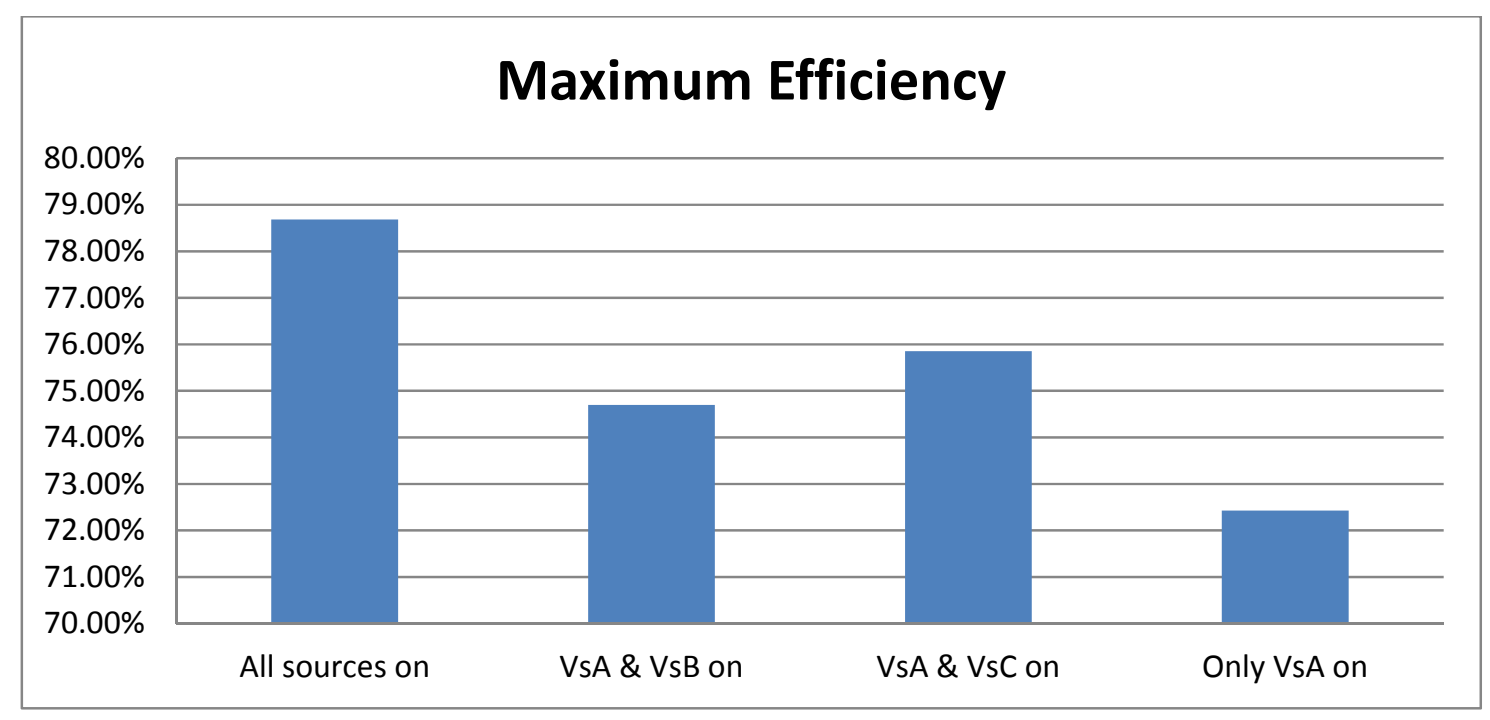

Figure 5-4. Maximum efficiency of MISO converter

Figure 5-5 to Figure 5-8 show the output voltage ripple in each input condition.

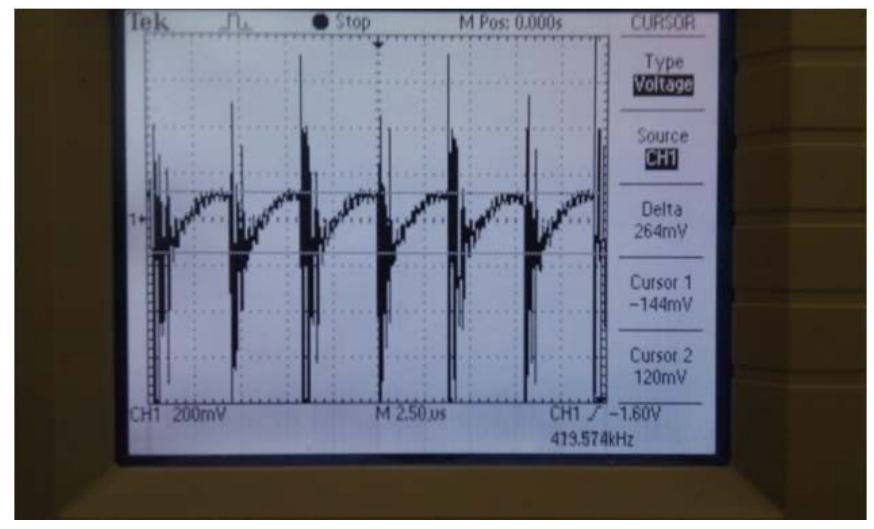

Figure 5-5. Output voltage ripple when MISO converter is powered by source A 


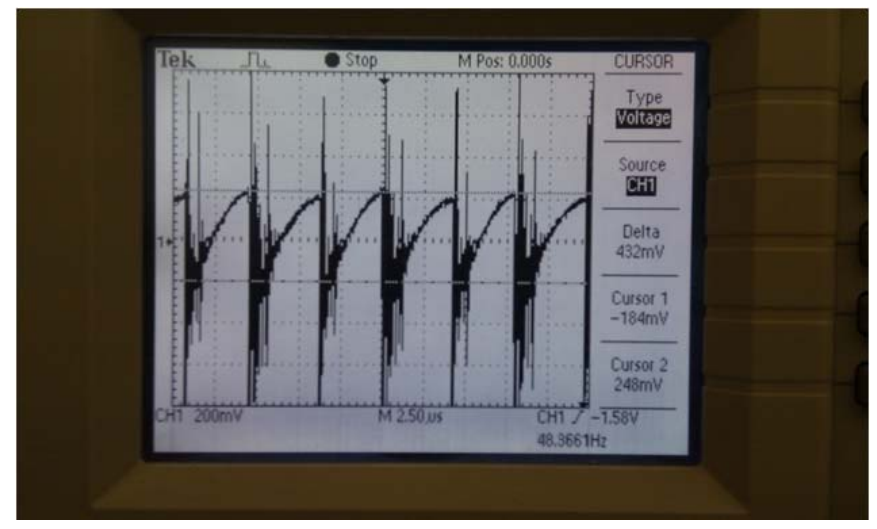

Figure 5-6. Output voltage ripple when MISO converter is powered by input A and C

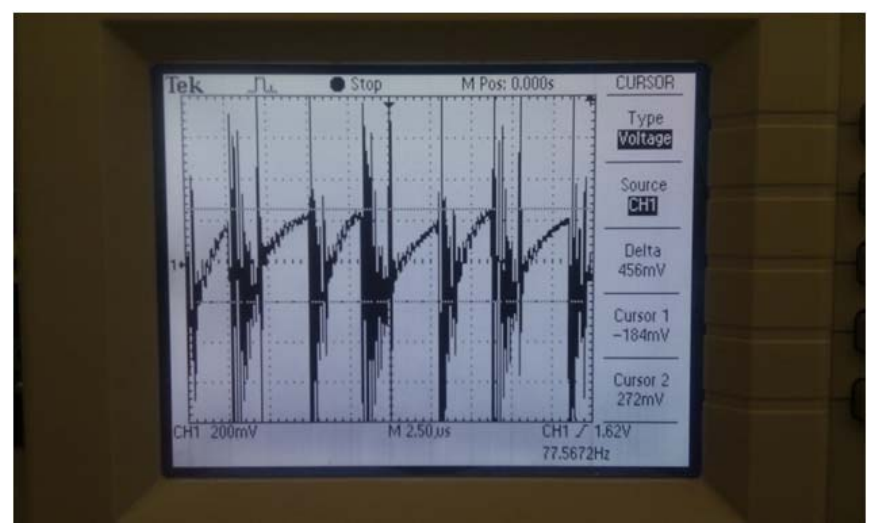

Figure 5-7. Output voltage ripple when MISO converter is powered by input A and B

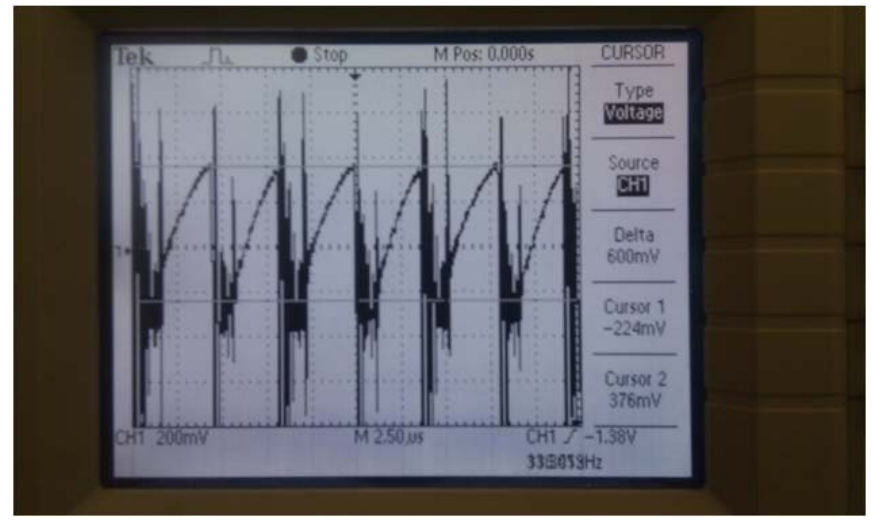

Figure 5-8. Output voltage ripple when MISO is powered by all input sources 
Figure 5-2 shows that the proposed MISO converter successfully converted three independent sources to a stable single output. When MISO is supplied by a single source, it can output $38.7 \mathrm{~W}$ to the load. Output voltage ripple for this case is captured in Figure 5-5 which yields the lowest for all cases. The output load regulation is $0.52 \%$ and efficiency is $72 \%$, which are both within the specified level. However, the total delivered output power is less than expected. The under power problem is due to the maximum pulse by pulse switching current monitored by the controller. As discussed in the previous chapter, the controller turns off all MOSFETs once the peak of the switching current exceeds $300 \mathrm{mV}$. Figure 5-9 shows the voltage waveform at the Current Sense (CS) pin of the controller when the MISO converter is powered by one single source.

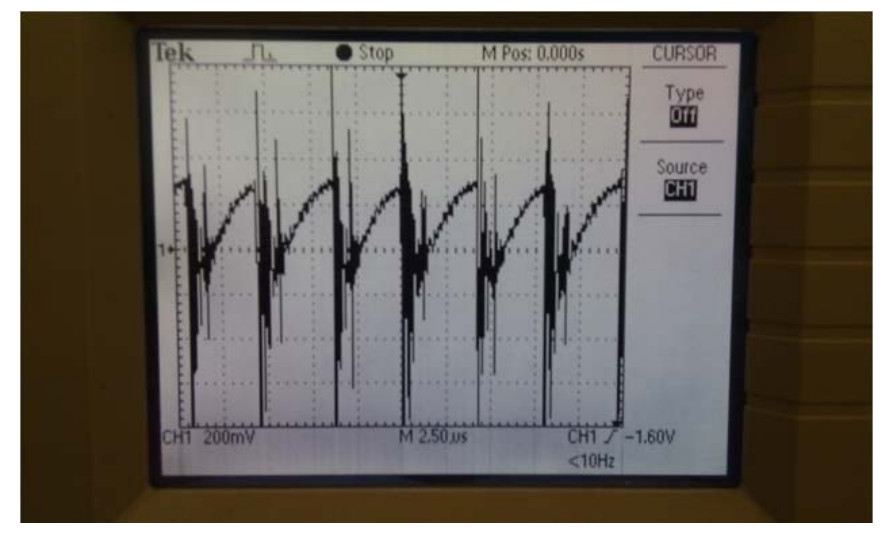

Figure 5-9. CS voltage waveform when MISO converter is powered by one source

As seen in Figure 5-9, the peak of the CS voltage reaches $300 \mathrm{mV}$ threshold when it outputs $38.7 \mathrm{~W}$. As a result, PWM cycle is terminated and output drops to zero. The peak voltage can be reduced by lowering the current sense resistance. By changing the current sense resistance to $0.25 \mathrm{~m} \Omega$, the output power can be increased to $43.8 \mathrm{~W}$. Figure 
5-10 shows the voltage waveform at the CS pin of the controller with $0.25 \mathrm{~m} \Omega$ sense resistor.

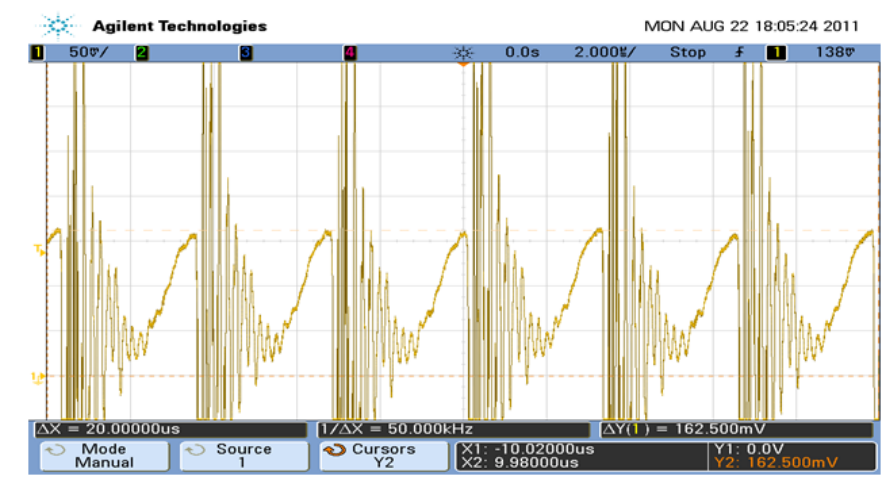

Figure 5-10. CS voltage waveform with $0.25 \mathrm{~m} \Omega$ sense resistor

In Figure 5-10, current sense voltage peak is reduced to $162 \mathrm{mV}$ and output power is increased. However, the output power is also limited by the noise in the circuit. In Figure 5-9, the voltage waveform contains a lot of high voltage spikes in the leading edge which are caused by the leakage inductance of the transformer and inductance induced by the layout traces. When one MOSFET turns off, its current drops at a steep di/dt resulting in a positive going spike. The voltage spike is defined in (5-4),

$$
\mathrm{V}_{\text {leakage }}=\mathrm{L}_{\text {leakage }}(\mathrm{di} / \mathrm{dt})
$$

As discussed in the last chapter, this high voltage spike can be discarded by adjusting the leading edge blanking time. However, in Figure 5-9, the longest voltage spike stays for at least $600 \mathrm{~ns}$ in a switching cycle. While the maximum blanking time supported by the controller is $320 \mathrm{~ns}$, most of the high voltage spikes false triggered the pulse-by-pulse comparator inside the controller and stops the PWM cycle. A soft start cycle restarts the PWM cycle after the soft start capacitor is discharged. In Figure 5-11, 
the trace connected from the CS pin of the controller to the voltage node of the sense resistor is shown in blue. The current sense trace was designed to run underneath the transformer on the layout so as to minimize the board size. However, high frequency switching noise generated by the transformer is induced to the trace and caused the high voltage spikes. In order to minimize the voltage spikes, primary current sense trace needs to be re-routed and shorten in order to avoid the switching noise.

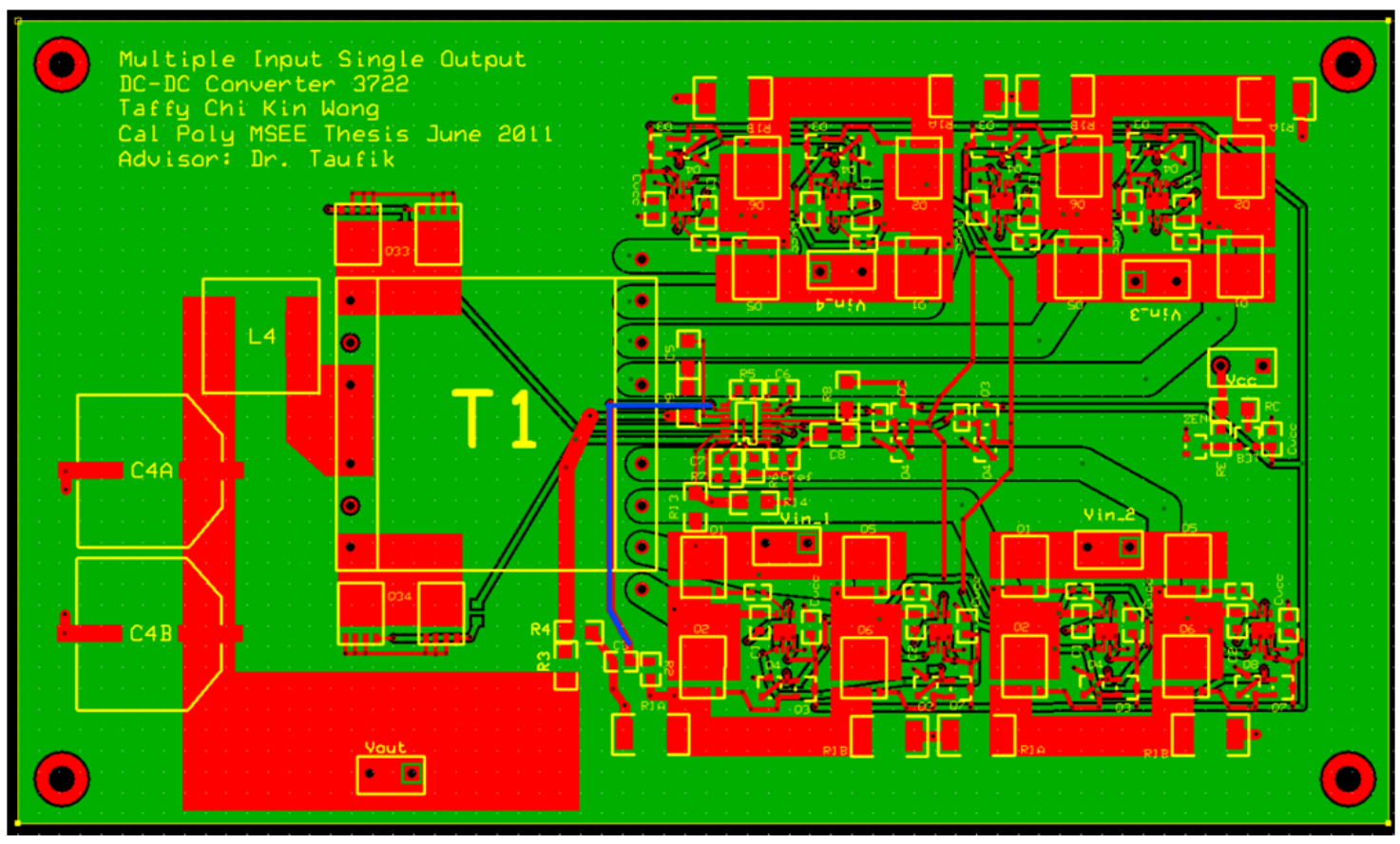

Figure 5-11. Layout of the MISO converter

When MISO converter is powered by two sources, the maximum output power of the MISO is increased. Output ripple for both cases (VsA and VsB on, VsA and VsC on) in Figure 5-6 and Figure 5-7 are also increased to $432 \mathrm{mV}$ and $456 \mathrm{mV}$. The increase of input sources improves the efficiency for both cases to $74.7 \%$ and $75.85 \%$. By comparing the two cases when the MISO is powered by two input sources, the output efficiency is less when it is powered by input source A and input source B. The drop in efficiency is due to 
the proximity loss inside the transformer. According to the sandwich winding pattern in Figure 4-3, NpA and $\mathrm{NpB}$ are constructed on the first layer while $\mathrm{NpC}$ and $\mathrm{NpD}$ are constructed on the third layer. When input $\mathrm{A}$ and input $\mathrm{C}$ are on, the designed $\mathrm{Np} / \mathrm{Ns} / \mathrm{Np} / \mathrm{Ns}$ sandwich pattern is maintained so the proximity loss is minimized. However, when only input A and input B are switched on, the sandwich pattern is changed to $\mathrm{Np} / \mathrm{Ns} / \mathrm{Ns}$. The two Ns windings in parallel create proximity effect and increase the AC resistance of the two windings. This causes power loss inside the transformer and decreases the efficiency.

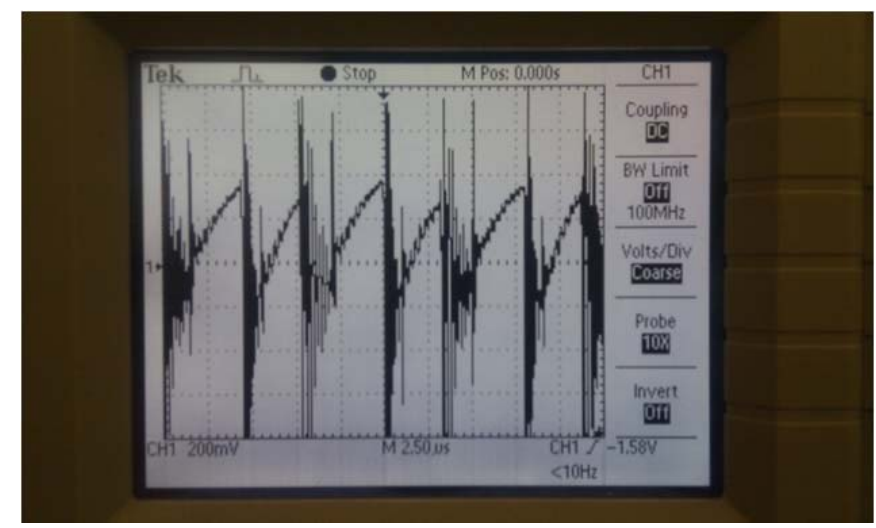

Figure 5-12. CS voltage waveform when MISO converter is powered by input A and B

Also, the output power is again limited due to the overcurrent function of the controller being false triggered by monitoring the CS pin of the controller. In Figure 5-12, the worst high voltage spike stays for 1us when it is powered by input source A and input source B. The controller once again terminates the PWM cycle and restarts the soft start cycle. The variation of the pulse width suggests that the overcurrent protection is false triggered and it varies the duty cycle. Figure 5-13 shows the current sense voltage waveform when MISO converter is powered by input A and input C. The duty cycle is 
constant so MOSFETs on the full bridge turn on longer and allow more power to transfer to the output. As a result, MISO converter outputs $18 \mathrm{~W}$ more when it is powered by input source A and input source C. In order to increase the output power, the leading edge voltage spike has to be minimized by removing the current sense trace away from the noisy component, such as the switching transformer.

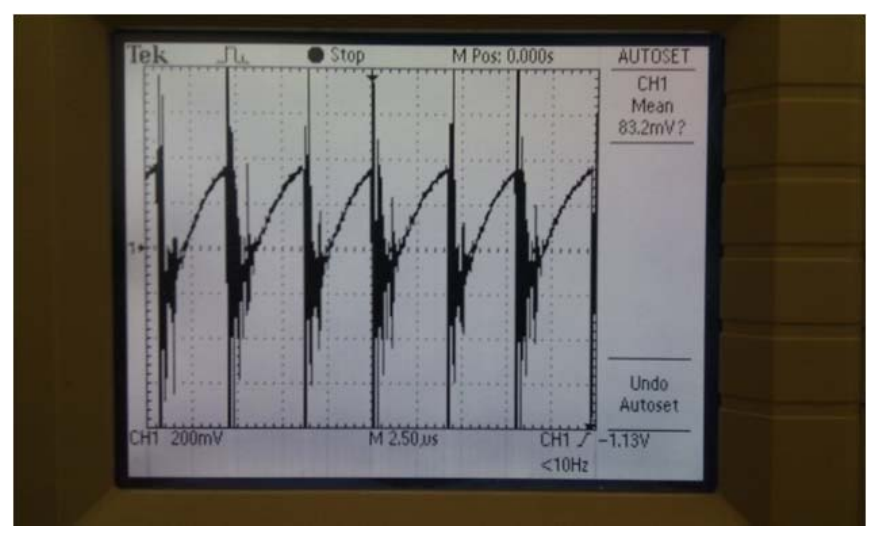

Figure 5-13. CS voltage waveform when MISO converter is powered by input A and C

The MISO converter outputs a maximum of $80 \mathrm{~W}$ when all input sources are on. Output ripple voltage peak to peak and voltage regulation are the highest in all cases; however, both are still within the specification. As the number of input sources increases to three, the efficiency increases to $78.68 \%$ which is the highest in all cases. Once again, output power is limited by voltage spikes in the leading edge of the current sense voltage waveform as evident from Figure 5-14. In Figure 5-14, the voltage spike in leading edge stays for 1.3 us which goes beyond the leading edge blanking time. The voltage spike reduces the duty cycle and false triggers the overcurrent protection of the controller. Also, the peak of the current sense voltage is hitting $300 \mathrm{mV}$ threshold and triggers the overcurrent protection. In order to increase the output power, the peak of the current 
sense can be reduced by lowering the sense resistance so as to decrease the error amplification. However, voltage spike requires an update on the existing layout which has been discussed above.

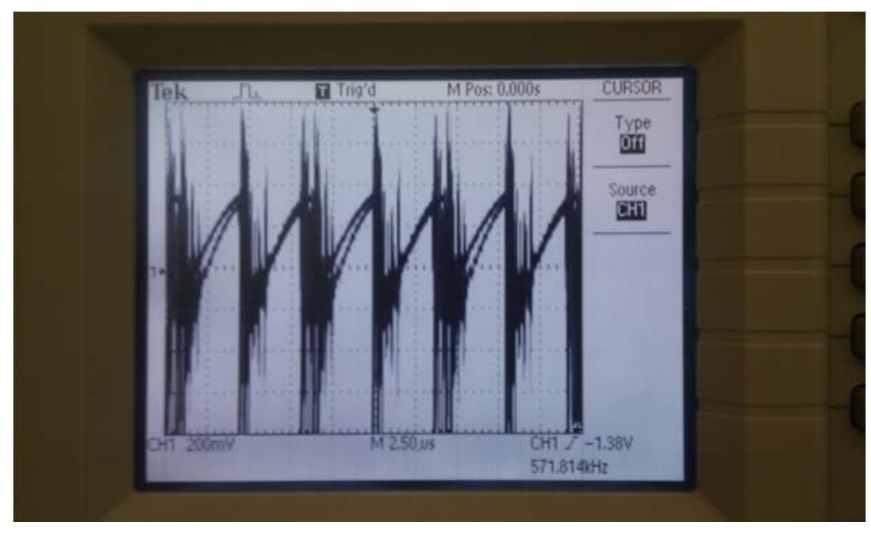

Figure 5-14. CS voltage waveform when MISO converter is powered by all sources 


\section{Improvements and Future Work}

Concluding from the previous chapter, the proposed MISO converter proves that the addition of power can be performed by the magnetic flux produced inside the core of the transformer. However, because of the voltage spikes induced by the noisy components near the sensing traces, overcurrent protection is false triggered and limits the output power to $80 \mathrm{~W}$. In order to increase the output power, several technical approaches to minimize the induced noise may be necessary as described in this chapter. .

As previously discussed, the current sense trace is routed underneath the switching transformer in the current layout. As a result, the trace is exposed to the noisy environment and picks up the noise induced by the noise generated component which is none other than the switching transformer. To minimize the noise effect, this trace needs to be re-routed and isolated from the noise. An improved layout is provided as shown in Figure 6-1. In the new layout, both the voltage feedback trace and primary current sense trace are re-routed to the lower left side of the switching transformer. Also, to ensure both traces are isolated from the surrounding noisy components, two ground traces are added on the layout. The newly added ground traces are shown in blue on Figure 6-1. Using a ground trace to isolate sensitive components from noise is commonly used on circuit design. By putting a ground trace between the noise component and the sensitive component, noise tends to induce to the ground and the sensitive component is isolated from the noise. In Figure 6-1, one ground trace is routed between the transformer and the two sensing traces. Another ground trace is routed between the two sensing traces and the switching node of input $\mathrm{A}$. Both the transformer and switching node switch at $100 \mathrm{kHz}$ 
which further generates switching noise. With the newly added ground trace, the voltage waveform at the current sense pin of the controller should be less than before.

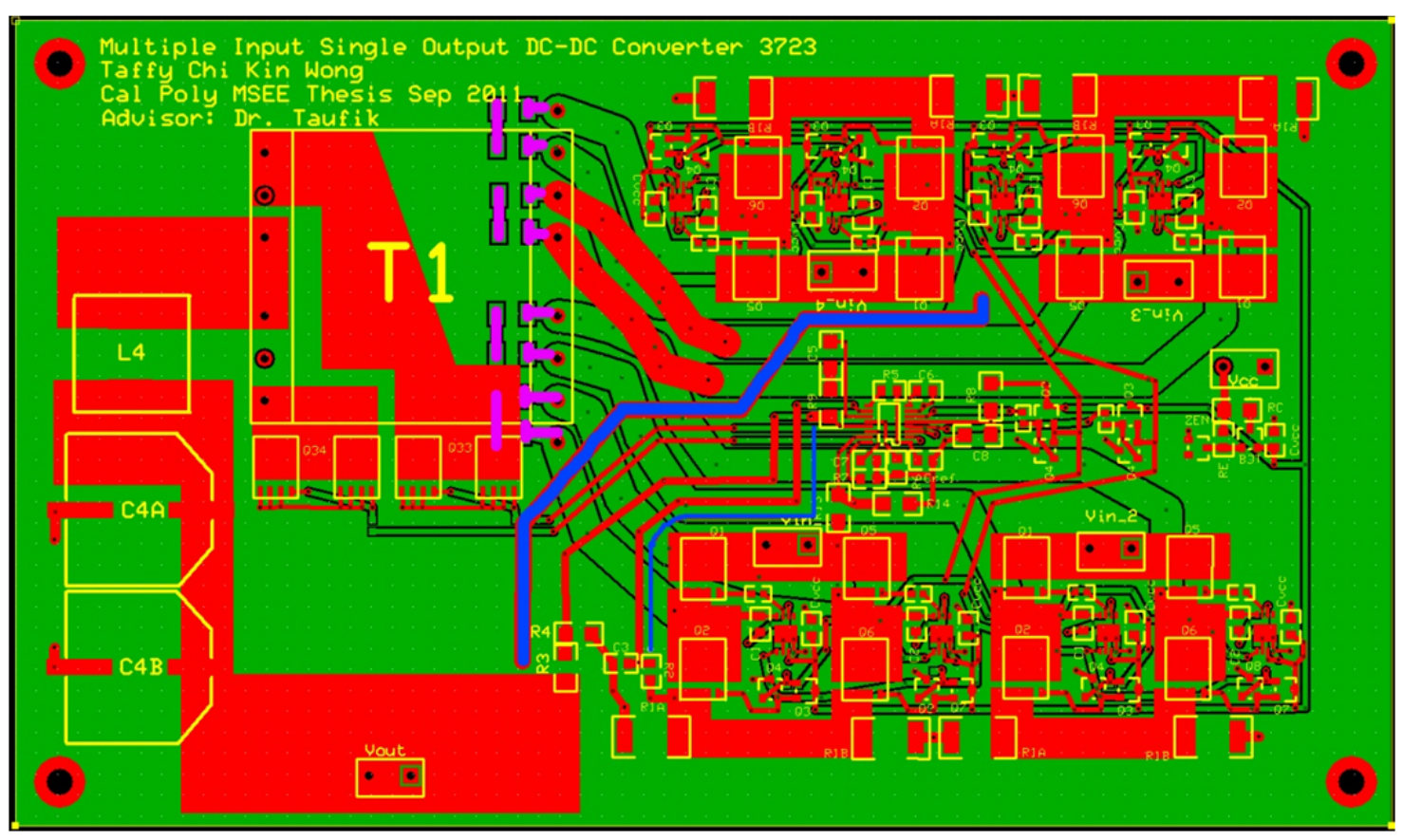

Figure 6-1. Improved layout of the MISO converter

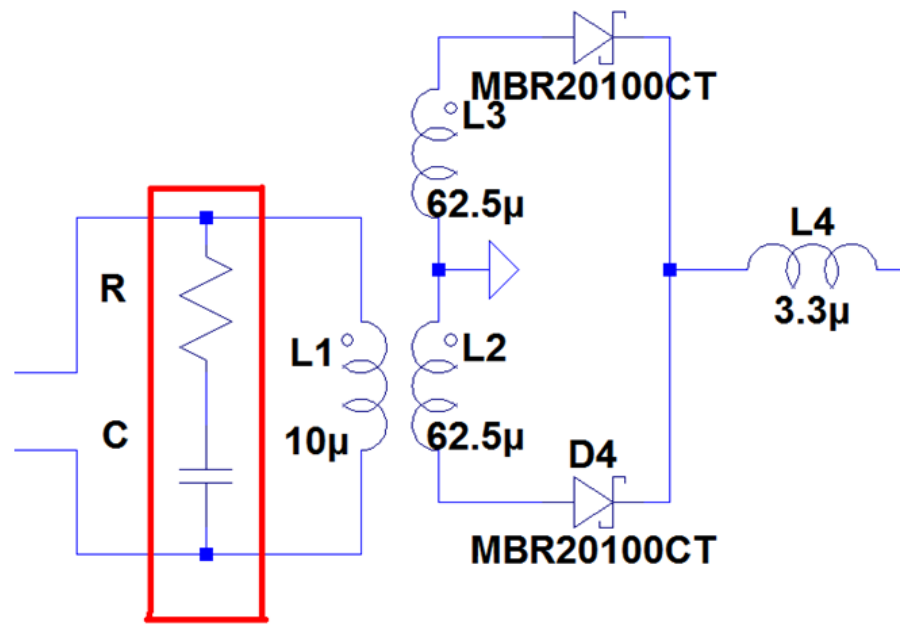

Figure 6-2. MISO transformer with additional primary RC snubber circuit 
The leading edge voltage spikes caused by leakage inductance from the transformer false trigger the overcurrent protection. To reduce the voltage spike, a RC snubber circuit is connected across each primary winding as shown in Figure 6-2. The snubber circuits are also included in the new layout as shown in purple in Figure 6-1. During the MOSFET's turn off transient, the additional snubber components R and C provide an alternative path for the primary switching current which slows down the rate of change $\mathrm{dI} / \mathrm{dt}$ in the MOSFET. According to equation (5-4), lowering the rate of change of current will reduce the voltage spike caused by leakage inductance.

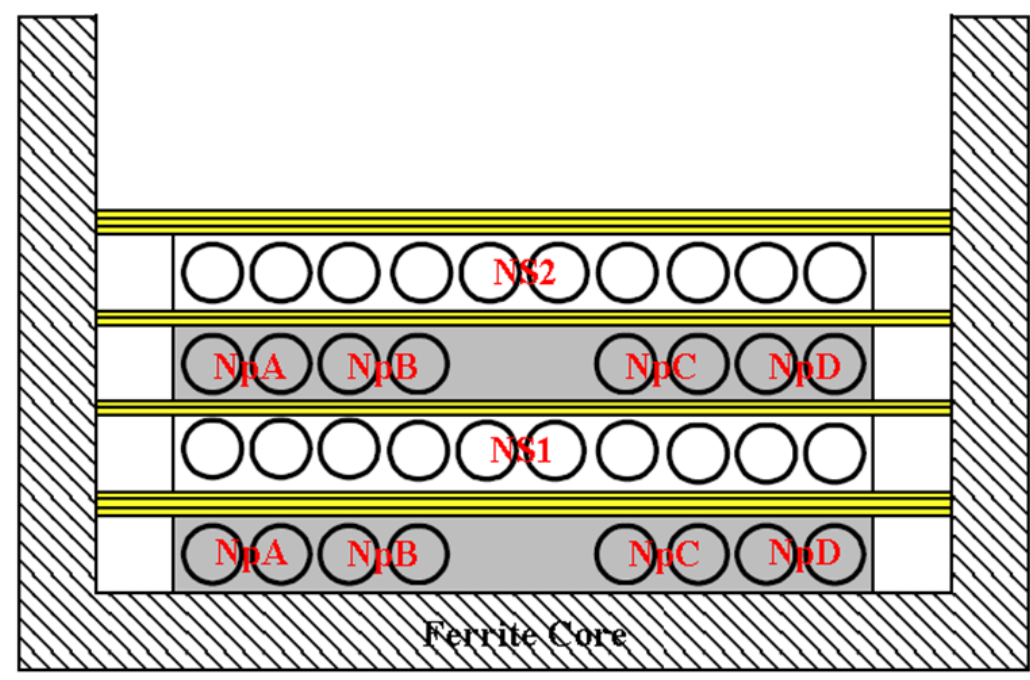

Figure 6-3. Improved MISO transformer sandwich winding

The efficiency of the MISO converter can be further increased by improving the sandwich winding pattern of the transformer. In the previous chapter, it was realized that the current sandwich winding pattern minimizes proximity effect only when the sandwich pattern $\mathrm{Np} / \mathrm{Ns} / \mathrm{Np} / \mathrm{Ns}$ is maintained. However, the current transformer construction retains the desired pattern only when all inputs are on or when input $\mathrm{A}$ and input $\mathrm{C}$ are on. 
Figure 6-3 shows an improved sandwich winding pattern of the transformer. In the new sandwich winding pattern, the first two turns of each input winding are wound on the first layer. This first layer is then covered by NS1. On top of NS1, the remaining two turns of each input winding will continue on the third layer. After that, NS2 is covered on the last layer. In this new sandwich pattern, $\mathrm{Np} / \mathrm{Ns} / \mathrm{Np} / \mathrm{Ns}$ winding pattern is always maintained no matter which input source is turned on. As a result, the proximity loss should be low for all input cases and the efficiency should therefore be improved.

Another critical loss in the circuit is caused by the output rectifiers. On the current MISO converter circuit, two schottky diodes are currently used as the output rectifiers to rectify the $\mathrm{AC}$ square wave from the transformer. Compared with fast diode and PN diode, Schottky diode's reverse recovery time is short and forward voltage drop is less. Since power loss is the product of square of voltage drop and inverse of Ron resistance, overall efficiency may be improved by using Schottky diode. However, power MOSFET Rds(on) resistance is much lower and it can switch on and off at high frequency. Therefore, to further improve the overall efficiency, synchronous rectification can be applied on the output rectifier. Synchronous rectification is supported by the LTC3722-1 controller used in MISO controller. The controller has two pins assigned to drive the power MOSFETs on the secondary side. The layout for the synchronous MOSFETS is also included in Figure 6-1 for the next revision of MISO controller.

The number of input sources can be expanded for the proposed MISO circuit; however, the power MOSFETs on the bridge have to be changed. According to LTC3722-1 controller datasheet, the controller has a 1A Totem pole MOSFET driver built inside the controller. As we have discussed in Chapter 4, an external totem pole is 
also used on the current MISO converter to boost the signal power. Instead of consuming additional power to boost the signal, the same signal can drive more MOSFET by reducing the gate charge $(\mathrm{Cg})$ inside the MOSFET. According to element laws:

$$
\begin{aligned}
& \mathrm{Q}=\mathrm{CV} \\
& \mathrm{I}=\mathrm{Cdv} / \mathrm{dt}
\end{aligned}
$$

Therefore,

$$
\mathrm{Q}=\text { Time } * \text { Current }
$$

Equation (6-3) shows that the current required to switch on the MOSFET is directly proportional to the gate charge. In the current MISO converter, Si7852DP from Vishay is used and its gate charge is $31 \mathrm{nC}$. The gate charge can be reduced by half by using RJK0651PB from Renesas. According to the datasheet, the gate charge of the power MOSFET from Renesas is $15 \mathrm{nC}$. By using RJK0651DPB, the gate driving current should now be reduced by half according to (6-3). As a result, the controller can drive more power MOSFETs and thus accept more input sources. 


\section{Conclusion}

This report proposes a new multiple-input single-output (MISO) DC-DC converter to receive three DC input sources and to convert them into a single DC output. The MISO converter employs the Full Bridge topology and it is aimed for use as the main converter for the DC house currently developed at Cal Poly. By using one single MISO transformer, the proposed converter successfully combines input powers from different input sources to a single output using the addition of magnetic flux produced inside the core of the transformer. Full bridge topology is chosen because it provides several benefits such as the need of only one winding per input sources in the transformer. This in turn keeps the size of the transformer small so that it requires less space on the circuit board. The MISO converter was built on a 6.5 " $\mathrm{x} 4$ " board which makes it portable and suitable for DC house application. Efficiency, output voltage peak to peak ripple and output load regulation data were also collected for different input scenario. The results suggest that both efficiency and output power increase as more input sources are used to supply power. In all four tested input cases, both output load regulation and output voltage ripple are low which guarantee the output quality.

Circuit layout is one of the most important design considerations in the proposed MISO converter. Since the controller uses current sense at the primary winding and voltage sense at the output to auto adjust its PWM duty cycle, it is important to ensure both signal information are protected from being corrupted by switching noise. However, this problem was not readily observed during the layout design. On the present layout, both current and voltage sensing traces are running closed to noisy components on the layout. The switching noise causes leading edge spikes in the current sense voltage 
waveform and false triggered the overcurrent protection. As a result, the maximum output power is limited to $80 \mathrm{~W}$ before the controller shuts down. The issue with voltage spikes was addressed and suggestions to minimize the spikes were laid out for future improvement.

In conclusion, this thesis demonstrates the ability and potential of the proposed MISO converter to accept input power from several different sources and then convert the power into one single output using one transformer. 


\section{BIBLIOGRAPHY}

[1] U.S. Energy Information Administration, "World Energy Demand and Economic Outlook" http://www.eia.doe.gov/oiaf/ieo/world.html.

[2] Katti Pradeep K; Khedkar Mohan K, "Towards Sustainable Energy Systems Integrating Renewable Energy Sources is the Key for Rural Area Power Supply" Power Engineering Conference, 2005. IPEC 2005. The 7th International, pp.1-104, 2005.

[3] Katti, P.K.; Khedkar, M.K., "Integrated Operation of Decentralised Resources for Rural Area Power Supply Applications" Transmission and Distribution Conference and Exhibition: Asia and Pacific, 2005 IEEE/PES, pp.1-6, 2005.

[4] Hanley, C.; Ross, M.; Foster, R.; Estrada, L.; Cisneros, G.; Rovero, C.; Ojinaga, L.; Verani, A., "Using renewable energy for rural connectivity and distance education in Latin America" Photovoltaic Specialists Conference, 2002. Conference Record of the Twenty-Ninth IEEE , pp.1481-1484, 2002.

[5] Grob, G.R., "Future Transportation with Smart Grids \& Sustainable Energy" Systems, Signals and Devices, 2009. SSD '09. 6th International Multi-Conference on, pp.1-5, 2009.

[6] Zhang Yanning; Kang Longyun; Cao Binggang; Huang Chung-Neng; Wu Guohong, "Renewable Energy Distributed Power System With Wind Power and Biogas Generator" Transmission \& Distribution Conference \& Exposition: Asia and Pacific, 2009 , pp.1-6, 2009.

[7] ABB Website, http://www.abb.com.

[8] Krueasuk, W.; Poungchingyam, A.; Sriamonkitkul, W.; Intarajinda, R.; Bhasaputra, P.; Pattaraprakorn, W.; , "Powerbike to Enhance Hybrid PV-Diesel System for rural primary school" Energy and Sustainable Development: Issues and Strategies (ESD), 2010 Proceedings of the International Conference on , pp.17, 2010.

[9] Chen, Y.-M.; Liu, Y.-C.; Wu, F.-Y.; Wu, Y.-E., "Multi-Input Converter with Power Factor Correction and Maximum Power Point Tracking Features" Applied Power Electronics Conference and Exposition, 2002. APEC 2002. Seventeenth Annual IEEE, pp.490-496 vol 1, 2002.

[10] Abd Malek, N.; Hasini, H.; Rahman, A.A.; Nasharuddin Mohd Jaafar, M., “An Improved Solar PV System for Malaysian Rural Electrification part I: Design and testing of solar PV with tracker and reflectors" Research and Development (SCOReD), 2010 IEEE Student Conference on, pp.452-457, 2010.

[11] Kathirvel, C.; Porkumaran, K, "Analysis and Design of Hybrid Wind-Diesel System with Energy Storage for Rural Application" IPEC, 2010 Conference Proceedings , pp.250-255, 2010.

[12] Anup, K.C.; Poudel, G.; Poudel, S.; Khadka, M., "Hydro Home System - an Inventory on Rural Electrification" Computer and Automation Engineering (ICCAE), 2010 The 2nd International Conference on, pp.338-341, 2010.

[13] Kwasinski, A., "Identification of Feasible Topologies for Multiple-Input DC-DC Converters" Power Electronics, IEEE Transactions on Volume: 24 , Issue: 3, pp.851-861, 2009. 
[14] Ou Ting-Chia; Lin Whei-Min; Huang Cong-Hui, "A Multi-Input Power Converter for Hybrid Renewable Energy Generation System" Sustainable Alternative Energy (SAE), 2009 IEEE PES/IAS Conference on , pp.1-9, 2009.

[15] Zhao Ruichen; Kwasinski, A., "Multiple-input single ended primary inductor converter (SEPIC) Converter for distributed generation applications" Energy Conversion Congress and Exposition, 2009. ECCE 2009. IEEE, pp.1847-1854, 2009.

[16] Yang Dongsheng; Ruan Xinbo; Li Yan; Liu Fuxin, "Multiple-input Full Bridge DC/DC Converter" Energy Conversion Congress and Exposition, 2009. ECCE 2009. IEEE , pp.2881-2888, 2009.

[17] Chiu Huang-Jen; Huang Hsiu-Ming; Lin Li-Wei; Tseng Ming-Hsiang, "A Multiple-Input DC-DC Converter for Renewable Energy Systems” Industrial Technology, 2005. ICIT 2005. IEEE International Conference on , pp.1304-1308, 2005.

[18] Liu Shengyong; Zhang Xing; Guo Haibin; Xie Jun, "Multiport DC/DC Converter for stand-alone photovoltaic lighting system with battery storage" Electrical and Control Engineering (ICECE), 2010 International Conference on , pp.3894-3897, 2010.

[19] Bottrill John, "How to Specify the Current Sense Resistor in a Converter using the UCC28083” Texas Instruments Application Report SLUA584, pp.1-6, 2010. 


\section{APPENDIX A}

The following information is specification data for transformer ferrite core PQ35/35:

\section{PQ Series PQ35/35 Cores}
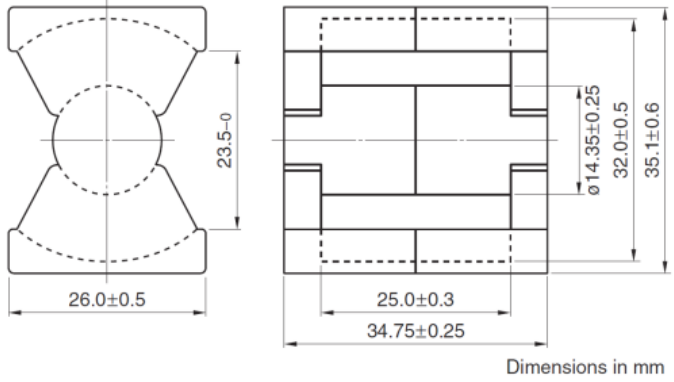

\section{PARAMETER}

\begin{tabular}{lllll}
\hline Core factor & $\mathrm{C} 1$ & $\mathrm{~mm}^{-1}$ & 0.448
\end{tabular}

\begin{tabular}{llll}
\hline Effective magnetic path length & $\ell \mathrm{e}$ & $\mathrm{mm}$ & 87.9 \\
\hline
\end{tabular}

$\begin{array}{llll}\text { Effective cross-sectional area } & \mathrm{Ae} & \mathrm{mm}^{2} & 196\end{array}$

Effective core volume $\quad$ Ve $\quad \mathrm{mm}^{3} \quad 17300$

\begin{tabular}{llll}
\hline Cross-sectional center pole area & Acp & $\mathrm{mm}^{2}$ & 162
\end{tabular}

$\begin{array}{llll}\text { Minimum cross-sectional center pole area } & \text { Acp min. } \text { mm² }^{2} & 156\end{array}$

\begin{tabular}{llll}
\hline Cross-sectional winding area of core & Acw & $\mathrm{mm}^{2}$ & 220.6 \\
\hline
\end{tabular}

Weight (approx.)

g 73

\begin{tabular}{llll}
\hline Part No. & AL-value $\left(\mathrm{nH} / \mathrm{N}^{2}\right)^{*}$ & Core loss $(\mathrm{W})$ max. & $\begin{array}{l}\text { Calculated output power } \\
\text { (forward converter mode) }\end{array}$ \\
\hline PC44PQ35/35Z-12 & $4860 \pm 25 \%(1 \mathrm{kHz}, 0.5 \mathrm{~mA})$ & $5.27\left(100^{\circ} \mathrm{C}\right)$ & $452 \mathrm{~W}(100 \mathrm{kHz})$ \\
\hline PC90PQ35/35Z-12 & $4700 \pm 25 \%(1 \mathrm{kHz}, 0.5 \mathrm{~mA})$ & $6.6\left(100^{\circ} \mathrm{C}\right)$ & $475 \mathrm{~W}$ \\
\hline PC95PQ35/35Z-12 & $7320 \pm 25 \%(1 \mathrm{kHz}, 0.5 \mathrm{~mA})$ & $7.12 / 5.98 / 7.12\left(25^{\circ} \mathrm{C} / 80^{\circ} \mathrm{C} / 120^{\circ} \mathrm{C}\right)$ & $500 \mathrm{~W}$ \\
\hline
\end{tabular}

NI limit vs. AL-value for PC44PQ35/35 gapped core (Typical)

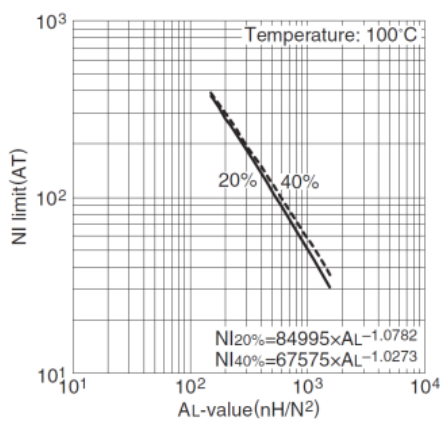

Note: NI limit shows the point where the exciting current is $20 \%$ and $40 \%$
AL-value vs. Air gap length for PC44PQ35/35 core (Typical)

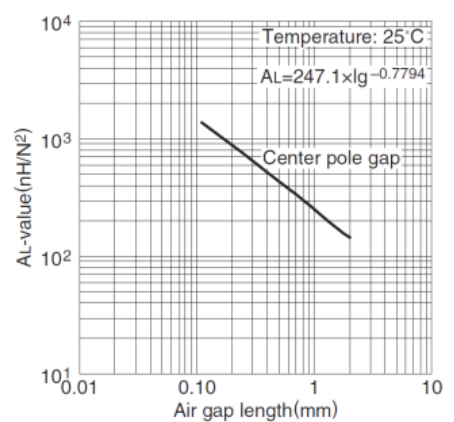

Measuring conditions • Coil: $₫ 0.4$ 2UEW 100Ts

- Frequency: $1 \mathrm{kHz}$

- Level. 0.5mA
Temperature rise vs. Total loss for PQ35/35 core (Typical)

(Ambient temperature: $25^{\circ} \mathrm{C}$ )

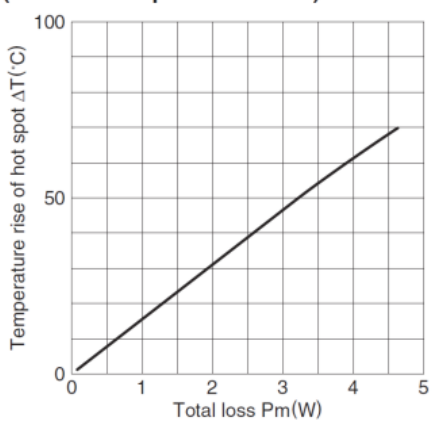

Note: The temperature rise is measured in the room whose temperature and humidity are (approx. $400 \times 300 \times 300 \mathrm{~cm}$ )

Measuring point

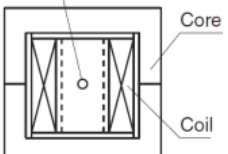




\section{APPENDIX B}

The following information is specification data for transformer ferrite core material:
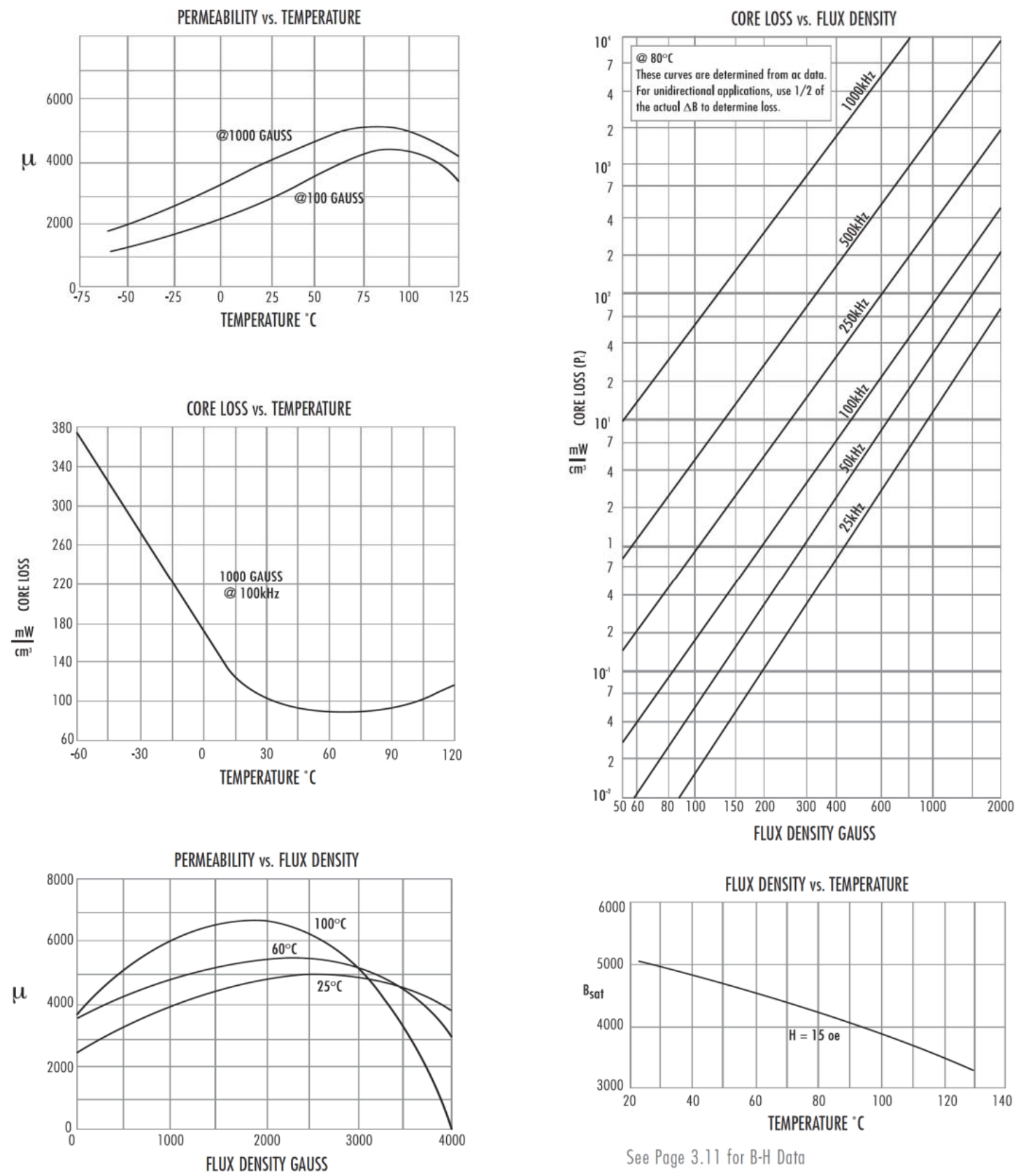

See Page 3.11 for B-H Data 